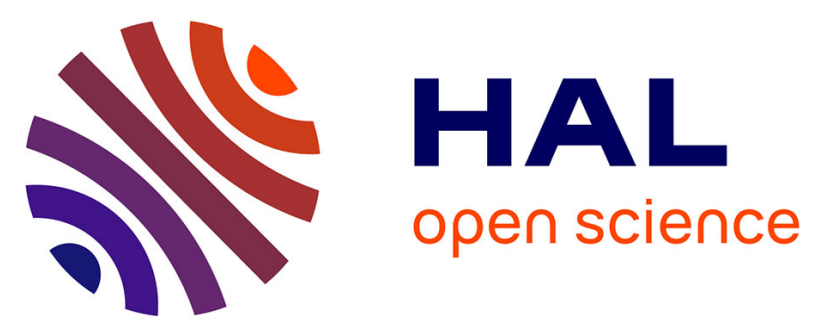

\title{
Kinematics of the Shoulder Girdle During Pointing: Coordination Between Joints and their Contribution to the Peri-Personal Workspace
}

Agnès Roby-Brami, Johanna V. Robertson, Alexandra Roeren, Marie Martine Lefèvre-Colau

\section{To cite this version:}

Agnès Roby-Brami, Johanna V. Robertson, Alexandra Roeren, Marie Martine Lefèvre-Colau. Kinematics of the Shoulder Girdle During Pointing: Coordination Between Joints and their Contribution to the Peri-Personal Workspace. Motor Control, 2016, 10.1123/mc.2015-0076 . hal-01312865

\section{HAL Id: hal-01312865 https://hal.sorbonne-universite.fr/hal-01312865}

Submitted on 9 May 2016

HAL is a multi-disciplinary open access archive for the deposit and dissemination of scientific research documents, whether they are published or not. The documents may come from teaching and research institutions in France or abroad, or from public or private research centers.
L'archive ouverte pluridisciplinaire HAL, est destinée au dépôt et à la diffusion de documents scientifiques de niveau recherche, publiés ou non, émanant des établissements d'enseignement et de recherche français ou étrangers, des laboratoires publics ou privés. 


\section{Kinematics of the shoulder girdle during pointing:}

\section{coordination between joints and their contribution to the \\ peri-personal workspace.}

Publié dans MOTOR CONTROL 2016 Apr 25. [Epub ahead of print]

Agnès Roby-Brami MD PhD ${ }^{1,2,3,4,5}$, Johanna V.G. Robertson PT PhD 5 , Alexandra Roren PT PhD ${ }^{4,6}$, Marie-Martine Lefèvre-Colau MD PHD ${ }^{4,6}$.

1- Sorbonne Universités, Université Pierre et Marie Curie Paris 06, Paris, France

2- CNRS, UMR 7222, Institut des Systèmes Intelligents et de Robotique, F-75005, Paris, France.

3- INSERM, U1150, Agathe-Institut des Systèmes Intelligents et de Robotique, F-75005, Paris France.

4- Cochin Hospital (AP-HP), Department of Physical Medicine and Rehabilitation, 75679 Paris Cedex 14, France.

5- Raymond Poincaré Hospital, AP-HP Department of Physical Medicine and Rehabilitation, 104 Boulevard Raymond Poincaré, 92380 Garches, France.

6- INSERM UMR 1153, ECAMO team, Centre de Recherche Épidémiologie et Statistique Sorbonne Paris Cité, Paris Descartes University, 75004 Paris, France.

Email addresses:

roby-brami@isir.upmc.fr

robertson.johanna@gmail.com

alexandraroren@yahoo.fr

marie-martine.lefevre-colau@cch.aphp.fr

Corresponding author: Agnès Roby-Brami

ISIR, Institute of Intelligent Systems and Robotics,

Université Pierre et Marie Curie, CNRS UMR 7222, Paris

4 place Jussieu, 75005 Paris

Tel :331442762 15 Cell : 33684680653 Fax :33 144275145

Running head: Shoulder girdle kinematics during pointing. 


\section{Abstract:}

This study explored the coordination between the components of the shoulder girdle (clavicle, scapula and humerus), and how they contribute to hand movement in the peripersonal space. Shoulder girdle motion was recorded in 10 healthy subjects during pointing movements to 9 targets in the peri-personal space, using electromagnetic sensors fixed to the trunk, scapula and upper arm. Most of the 9 degrees of freedom (DoF) of the shoulder girdle were finely scaled to target position. Principle component analysis revealed that the $6 \mathrm{DoF}$ of scapula-thoracic motion were coordinated in three elementary patterns (protraction, shrug and lateral rotation). The ratio of gleno-humeral to scapulo-thoracic global motion was close to 2:1. A direct kinematic procedure showed that if no scapular motion occurred, the workspace would be reduced by $15.8 \mathrm{~cm}$ laterally, $13.7 \mathrm{~cm}$ vertically and $4.8 \mathrm{~cm}$ anteriorly. Scapulothoracic motion should be taken into account when investigating the physiology of upper-limb movements.

\section{Keywords:}

motion analysis, redundancy, direct kinematics, scapula, clavicle, workspace 


\section{Background}

The human upper limb has a large number of DoF with much redundancy (Bernstein, 1967). The shoulder girdle is particularly complex since it is composed of three bones: the humerus, the scapula and the clavicle (Kapandji, 1980). The spherical head of the humerus inserts into the glenoid fossa of the scapula, creating a ball and socket joint with 3 degrees of freedom (DoF), the Gleno humeral joint (GH) (Codman, 1934 ). The two clavicular joints (Sterno-clavicular, and Acromio-clavicular), which each have $3 \mathrm{DoF}$, link the scapula to the thorax (Ludewig et al., 2009). In addition, there is a pseudo-joint formed by the surface of the scapula over the ribs and the muscles (scapulo-thoracic joint, ST), creating a closed kinematic chain (Lenarcic \& Stanisic, 2003; Seth, Matias, Veloso, \& Delp, 2015).

However, detailed analyses of the motion within the shoulder girdle have often been limited to elevation of the arm in the plane of the scapula or in the frontal (abduction) or sagittal (flexion) planes (e.g. Ludewig et al., 2009; Robert-Lachaine, Marion, Godbout, Bleau, \& Begon, 2015). Early studies of scapular motion (using goniometry or inclinometry) described a ratio of movement of 2:1 between $\mathrm{GH}$ and ST rotations during planar arm elevation. This ratio is termed "scapulo-humeral rhythm" (Codman, 1934; Inman, Saunders, \& Abbott, 1996). It is generally agreed that scapulo-humeral rhythm varies with the degree of elevation such that ST rotation occurs mostly during larger amplitudes of elevation (McQuade \& Smidt, 1998; Talkhani \& Kelly, 1997). The development of 3D methods of motion analysis using external sensors during the last decade facilitated the study of motion of the different structures of the shoulder girdle (reviewed in Roren et al., 2015). ST motion can be recorded using a 6 DoF sensor (or a cluster of 3DoF sensors or markers) fixed on the skin over the acromion process, after calibration of the relative positions of defined scapular landmarks. This method, named the acromial method, has been reviewed in (Lempereur, Brochard, 
Leboeuf, \& Remy-Neris, 2014). These techniques demonstrated that there is a complex pattern of 3D rotations and translations of the scapula relative to the trunk during planar arm elevation (Fayad et al., 2006; Ludewig, Behrens, Meyer, Spoden, \& Wilson, 2004; Ludewig, Cook, \& Nawoczenski, 1996; McClure, Michener, Sennett, \& Karduna, 2001; Pronk, van der Helm, \& Rozendaal, 1993; Robert-Lachaine et al., 2015; Roren et al., 2015; van der Helm \& Pronk, 1995). This was confirmed by invasive methods involving the insertion of pins into bones (Karduna, McClure, Michener, \& Sennett, 2001; Ludewig et al., 2009; Lawrence, Braman, Staker, Laprade, \& Ludewig, 2014; McClure et al., 2001) or x-ray imaging (Giphart et al., 2013). However, recent studies involving x-ray imaging of the GH joint have generally focused only on translation of the humeral head during joint rotations (Giphart et al., 2013).

Motion of the crank-shaped clavicle is particularly difficult to measure using external sensors. The only truly accurate method for the quantification of 3D rotations of the sternoclavicular and acromio-clavicular joints is invasive, involving the insertion of pins in the bones (Lawrence, Braman, Staker, Laprade, \& Ludewig, 2014; Ludewig et al., 2009). We previously developed an indirect method to analyze the function of the clavicle and scapula together. Six DoF can be measured by quantifying 3D rotations of the scapula along with the displacement of its center (Roren et al., 2015). Using the acromial method with a 6 DoF electromagnetic sensor and to evaluate large shoulder movements (Roren et al., 2015), we showed that the rotation of the scapula and the translation of its center were coupled, and we suggested that this was the result of the constraints of the curved thoracic surface (Roren et al., 2015). This closed chain description of the shoulder complex is geometrically correct since it does not involve any hypothesis regarding the position of the instantaneous axis of rotation. It is consistent with the biomechanical model recently proposed by Seth et al. (Seth et al., 2015). 
The purpose of the present study was to use the same kinematic method to study physiological motion of the shoulder girdle during goal directed movements in the peripersonal space. Coordination between the different components of the shoulder girdle during reaching in 3D space is poorly understood. Most previous studies have overlooked the contribution of the clavicle and scapula, reducing the shoulder to a 'humero-thoracic joint' (HT) (Desmurget \& Prablanc, 1997; Desmurget et al., 1995; Gielen, Vrijenhoek, Flash, \& Neggers, 1997; Medendorp, Crawford, Henriques, Van Gisbergen, \& Gielen, 2000; Nishikawa, Murray, \& Flanders, 1999; Rosenbaum, Meulenbroek, Vaughan, \& Jansen, 1999; Soechting, Buneo, Herrmann, \& Flanders, 1995; van der Steen \& Bongers, 2011). A few studies used Factor Analysis or the Uncontrolled Manifold approach to analyze motor synergies, however they did not present the specific variations of the shoulder DoFs relative to the spatial parameters of the task (Reisman \& Scholz, 2006; Tseng, Scholz, \& Schoner, 2002; Tseng, Scholz, Schöner, \& Hotchkiss, 2003; Yang, Scholz, \& Latash, 2007). Coordination within the shoulder girdle has also been studied during specific movements to test the impact of shoulder pathology on function (Aizawa et al., 2010; Magermans, Chadwick, Veeger, \& van der Helm, 2005; Roren et al., 2012) or to investigate physiological movement during sporting activities (particularly overhead throwing e.g. Seminati, Marzari, Vacondio, \& Minetti, 2015).

There is thus a lack of data on shoulder girdle kinematics during common goal directed movements in the 3D workspace within arm's reach. Such knowledge is important for the analysis of upper-limb motor control, particularly to determine to which extent the scapula participates in generating shoulder range of motion versus providing postural stability (Veeger \& van der Helm, 2007). The integration of ST motion in the kinematic chain for relatively small movements has significant consequences on both the biomechanical modeling and physiological aspects of motor control. The dynamics of the upper-limb are completely 
changed if the moments and forces generating the movements are produced more proximally by a larger number of muscles, but with a larger lever arm (Zatsiorsky, 2002). Integrating ST into the kinematic chain implies that the neural control of hand movements in space involves the proximal muscles controlling the scapula. In addition, since the shoulder complex includes a closed chain, the mechanical constraints caused by the thoracic surface should be taken into account in the analysis of stability and mobility of the shoulder girdle (Seth et al., 2015).

Globally, the shoulder complex illustrates the high redundancy of the motor system (Bernstein, 1967) and the interaction between the neural and biomechanical determinants of its control. Some evidence suggests that movements are planned as final reference postures involving all the joints of the limb (Desmurget \& Prablanc, 1997; Feldman, 1998; Rosenbaum, Meulenbroek, Vaughan, \& Jansen, 2001). In this framework, it is important to analyze how the position and orientation of the scapula, which is the most proximal segment of the upper-limb, are tuned as a function of the 3D spatial position of the target.

The aim of this study was to describe the coordination of the different elements of the shoulder girdle and how they contribute to the $3 \mathrm{D}$ movement of the hand in the peri-personal workspace. Our first hypothesis was that the motion of the scapula would contribute largely to the movement of the hand in space, even for relatively low and close targets. Our second hypothesis was that during pointing movements, scapula rotation and translation of its center would be coupled because of the constraints of the curved thoracic surface, as previously demonstrated during larger arm movements (Roren et al., 2015).

To this purpose, we calculated the range of motion of the different DoF of the shoulder girdle and the ratio of the GH to ST global angles during pointing movements. PCA was performed to analyze coupling between the DoF of the scapula. In addition, we used a direct kinematic procedure (Hanneton, Dedobbeler, Hoellinger, \& Roby-Brami, 2011) to quantify the contribution of the shoulder girdle to the displacement of the hand in space. None of these 
aspects of scapula-thoracic motion had been previously fully investigated during movements in the peri-personal workspace.

\section{Methods}

\section{Subjects}

Ten right-handed healthy subjects with no neurological or orthopaedic pathology of the upper arm were included. Five subjects were female and mean age was 51 years (range 2971). These subjects were the control group in a study of stroke patients presented in a previous paper (Robertson, Roche, \& Roby-Brami, 2012). Ethical approval was obtained for the study and all subjects gave informed consent.

\section{Experimental set up and task}

The participants were comfortably seated on a chair adjusted so that the table was approximately level with the navel. Movements of both arms were recorded in a controlled balanced order. Subjects wore a wrist splint to which a pointer was attached, mimicking an extended index finger, in order to limit variability due to the distal joints. The trunk was fixed to a chair using a wide strap that limited trunk flexion.

The starting position was with the hand placed on a red cross marked on the table in line with the shoulder, the forearm in mid-prone and the elbow flexed to $90^{\circ}$. Targets consisted of $1 \mathrm{~cm}$-wide red tape wrapped around a vertical stick of $1.5 \mathrm{~cm}$ diameter. The nine targets covered the typical workspace of the upper-limb with 3 forward and 6 lateral targets as indicated on Figure 1A-B. Target distance was adjusted for each subject as a function of anatomical arm length, measured from the acromion process to the end of the pointer. There were 3 close (at $65 \%$ of arm length) and 3 far targets (at $90 \%$ of arm length) placed $7 \mathrm{~cm}$ above the surface of the table and 3 high targets (level with the subject's acromion) positioned above the far distance. Targets were presented in a standardized order (close-middle, far- 
internal, high-external, far-middle, close-external, high-internal, close-internal, far-external, high-middle).

Subjects were instructed to touch the target with the tip of the pointer at a self-selected speed, with the wrist in a mid-prone position. The movement was carried out with eyes open. One familiarization trial was allowed then 3 repetitions of each movement were recorded.

\section{Data collection}

A 6-degree-of-freedom electromagnetic tracking device, the Polhemus Fastrak (SPACE FASTRAK, Colchester, VT, USA) was used to record the kinematic data at $30 \mathrm{~Hz}$. The transmitter, fixed under the table, gives the global frame of reference. Polhemus sensors were attached to each subject using tape on the manubrium, the acromion process, the upper third of the humerus (attached to a custom-made velcro cuff) and on the dorsum of the wrist splint. This method, which involves external markers, is sensitive to artifacts caused by skin sliding, however the level of error is considered to be acceptable for movements below $100^{\circ}$ of elevation following comparisons with invasive techniques involving sensors inserted directly into the bones (Lawrence et al., 2014; Ludewig et al., 2009), and biplane fluoroscopy (Giphart et al., 2013).

\section{Computation of the 3D positions of the body landmarks}

The initial calibration procedure was performed before the experiment with the subjects sitting. Bony landmarks of the trunk, scapula and upper arm were digitized in accordance with international recommendations (van der Helm, 1997) (Figure 2A), as well as the tip of the "finger" pointer, which was rigidly fixed to the splint (Figure 1C). The local coordinates of each body landmark were computed in the reference frame of the sensor fixed to the corresponding segment. The position of the center of rotation of the gleno-humeral joint was computed using a regression procedure on the data points recorded during circumduction movements of the arm (Biryukova, Roby-Brami, Frolov, \& Mokhtari, 2000). 
The 3D position of each point was then computed at each instant by projecting its local coordinates in the global reference frame using the instantaneous position and orientation of the sensor. The 3D position of the geometrical center of the scapula and the thorax were also computed (see Appendix 1). Appropriate geometrical transformations were used to project left side data on the right side. The 3D position of the targets was also calibrated.

\section{Characterization of initial and final shoulder postures}

Shoulder posture was measured at the onset of movement (initial posture) and when the subject pointed at the target (final posture). The times were automatically detected using the velocity profile of the hand (with a threshold of $0.05 \mathrm{~m} / \mathrm{s}$ ) then visually checked and validated using an interactive custom-made program. Movement accuracy was calculated as the 3D distance between the tip of the pointer and the target at the time of pointing. Displacement of the pointer-tip during the movement was also calculated.

The angles describing the initial and final posture of the shoulder complex were calculated. To that purpose, the relative orientations of the segments were computed according to the international ISB protocol and expressed as sequences of three ordered rotations (Euler angles (van der Helm, 1997) (Figure 2B). The orientation of the trunk relative to the global reference frame is expressed as flexion-extension, lateral bending and axial rotation. The orientation of the scapula relative to the trunk (scapulo-thoracic joint, ST) is expressed as the three ordered Euler angles: internal-external rotation, medial-lateral rotation and antero-posterior tilt. The position of the center of the scapula was also computed relative to the center of the thorax in the reference frame of the thorax (Roren et al., 2015). The orientations of the upper-arm relative to the scapula (gleno-humeral joint, $\mathrm{GH}$ ) and relative to the trunk (humero thoracic joint, HT) are expressed as the three ordered Euler angles: horizontal abduction, elevation and axial rotation. Elbow flexion-extension and prono-supination angles were computed within the direct kinematic procedure (see infra), but are not presented here. 


\section{Coordination within the shoulder girdle}

Classically, coordination between the ST and GH joints is quantified by the ratio of GH elevation to ST lateral rotation during planar elevation movements. This method is not suitable for the study of 3D movements involving complex shoulder rotations. Instead, we used the formalism of axis-angle (see Appendix 2) to compute the global angles of the GH, ST and HT joints during pointing. The rotation matrices for each joint were computed by projecting the matrix describing the final orientation of the segment in the matrix describing its initial orientation. The global rotation angles of ST, GH and HT were then computed according to the formula given in Appendix 1.

The dimensionality of ST motion was investigated by Principal Component Analysis (PCA). Anatomically, ST motion depends on the coordination of both clavicular joints (Sterno-clavicular, and Acromio-clavicular: 6 DoF). ST motion was quantified by 6 DoF (3 Euler angles and 3D displacement of the center of the scapula). PCA was performed on the data for all the subjects and conditions (data input matrix of 6 columns and 180 lines: 10 subjects $\mathrm{x} 2$ sides $\mathrm{x} 9$ targets) with varimax transformation (Statview software). This analysis yields the amount of variance explained by each PC and the correlation between principal components (PCs) and DoF.

\section{Direct kinematic procedure}

The influence of scapula rotations on the extent of the hand workspace was studied using a direct kinematic procedure. This procedure involves the computation of the position of the end-effector of a multi-link chain from the joint rotation values. We used individualized direct kinematic models fully described in a previous study (Hanneton et al., 2011) and summarized in Appendix 3. Briefly, the kinematic chain was defined by the initial position of the bony landmarks of the trunk, scapula, arm and forearm of each subject, and the endpoint was the tip of the pointer. The time course of the rotations measured for each DoF during the real 
movement was fed into the model for computation of the resulting displacement of the endpoint in the global reference frame. The accuracy of the model was quantified by comparison of the computed to the measured hand movements.

In the present study, a direct kinematic simulation was carried out for all the pointing movements performed by each participant. Pointer displacement was computed by the direct model in the global 3D frame, and then reported to its initial position. The computed and measured pointer movements were compared on an individual basis. The direct simulations were repeated with a reduced kinematic model: the time course of joint rotations fed into the direct model were modified so that the rotations between the thorax and the scapula remained constant (i.e. equal to the initial posture, measured at the beginning of the recording). This reduced model simulated a 'humero-thoracic joint' (i.e. no scapula), with the position of the center of GH fixed relative to the thorax. The contribution of ST rotations to the hand workspace was quantified by comparison of the output of the reduced model to the measured pointer movement, independently from the trunk and more distal upper-limb rotations (that were the same during the execution and simulation of the movement).

\section{Statistics}

The means of the three trials to each target were averaged for use in the statistical analyses.

Three factors ANOVA was performed with subjects as repeated measures. Range of motion (2 levels: initial and final shoulder postures) Side (2 levels), Target (9 levels), and Model (2 levels) were the independent variables. The dependent variables were the variables that described the posture of the shoulder girdle (Euler angles, global rotation angles, position of the center of the scapula) and the positions of the tip of the pointer (measured and computed). Post-Hoc analysis was performed with Two Factors ANOVA (Side and Target) separately for the initial and final postures, and Tukey-Kramer tests. Because of the large 
number of variables involved (3 DoF for GH, 6 DoF for ST, and 2 sides) we used a Bonferoni correction with an alpha level of 0.004 for ST and 0.008 for the other 3 DoF measures.

Regression analyses were used to study the relationship between global GH and ST angles as a function of the global HT angle.

\section{RESULTS}

\section{Motion of the structures of the shoulder girdle during pointing}

As shown in Figure 3, initial ST posture varied slightly with the target. Mean initial posture for the right side was: ST internal rotation: $32.2^{\circ} \pm 0.4$; ST lateral rotation: $10.3^{\circ} \pm 0.7$ and ST tilt $-8.4^{\circ} \pm 0.4$ (i.e. anterior tilt); GH elevation $9.8^{\circ} \pm 0.7$. Most rotation angles varied during pointing. The trunk flexed (particularly for far and high targets) and rotated axially internally (particularly for internal targets). The scapula rotated internally (particularly for internal targets), laterally (particularly for high targets) and the initially anterior tilt tended to decrease. The gleno humeral elevation also varied with the distance and direction of the target. The results of the statistical analyses are provided in Table 1 and developed below.

\section{Range of motion during pointing.}

Trunk flexion $\left(1.9^{\circ} \pm 0.1\right)$ and axial rotation $\left(1^{\circ} \pm 0.1\right)$ contributed significantly to the movement (Significant effect of Range and Target 72,1=56.4 and F72,8=6.3, p<0.0001, with Range $x$ Target interactions F72,8=18.6, $\mathrm{p}<0.0001$, Table 1A), but lateral bending did not.

Most rotational DoF of the shoulder complex contributed significantly to pointing. This was the case for ST internal $\left(7^{\circ} \pm 0.3\right)$ and lateral $\left(6.4^{\circ} \pm 0.3\right)$ rotations (Range effect F72,1=360.8, F72,1=167.2) and GH elevation $\left(19.4^{\circ} \pm 0.9\right.$, Range effect F72,1=204.7 $\mathrm{p}<0.0001$ ). At movement initiation, the upper-arm was near vertical, this resulted in a frequent occurrence of gimbal-lock for $\mathrm{GH}$ horizontal abduction and axial rotation (in 3 
subjects for the right side and 6 subjects for the left side). Statistical analyses on the initial posture and range of motion were therefore not performed on those $\mathrm{DoF}^{1}$.

The center of the scapula also moved during pointing as shown on Figure 4. There was a significant Range effect on the lateral and 3D displacements (F72,1=148.9, p<0.0001 and F72,1=141.6 respectively, $\mathrm{p}<0.0001$,Table 1B). The global 3D displacement varied from 0.5 $\mathrm{cm}$ for the Close External target to $2.1 \mathrm{~cm}$ for the Far-Internal target.

There was no significant effect of Side.

\section{Initial posture}

The initial position of the pointer remained stable during the experiment with only small (< $0.5 \mathrm{~cm}$ ) differences. The initial posture varied slightly with the Target (thick line on Figure 3). This was significant for trunk flexion-extension $\left(F 72,8=4 \mathrm{p}<0.001\right.$, maximum difference $\left.1.3^{\circ}\right)$ and ST lateral rotation $\left(\mathrm{F} 72,8=9.4, \mathrm{p}<0.0001\right.$, maximum difference of $\left.1.3^{\circ}\right)$. There was no significant effect of Side.

\section{Final posture.}

Pointing accuracy was measured by the distance between the final position of the pointer and the target. Mean error varied with Target (two Factors ANOVA F72,8=7.86, $\mathrm{p}<0.0001$ ) but remained relatively low (between 0.8 to $1.5 \mathrm{~cm}$ ).

There was no effect of Side on the final trunk or shoulder girdle postures.

Final trunk orientation depended on the target. Despite the restraining belt, the trunk was more flexed for far than for close targets $\left(F 72,8=9.1 \mathrm{p}<0.0001\right.$, maximum difference $\left.2.3^{\circ}\right)$ and more internally rotated for internal than for external targets $(\mathrm{F} 72,8=20.5, \mathrm{p}<0.0001$, maximum difference $3 \cdot 6^{\circ}$ ).

\footnotetext{
${ }^{1}$ This problem does not affect the measure of the final posture or that of the global GH rotation.
} 
The final orientation of all the structures of the shoulder girdle varied with Target (Table 2). There was a significant effect of Target for ST internal-external rotation $(F 72,8=89.7$, $\mathrm{p}<0.0001)$ and medial-lateral rotation $(\mathrm{F} 72,8=92.5, \mathrm{p}<0.0001)$ but not for antero-posterior tilt. Internal rotation was mainly related to target direction: it was greater for internal than for external targets, particularly for high targets $\left(47.6 \pm 1.6^{\circ}\right.$ versus $\left.39.5 \pm 1.6^{\circ}\right)$. Lateral rotation was greater for high $\left(22.9 \pm 0.9^{\circ}\right)$ than for far $\left(17 \pm 0.9^{\circ}\right)$ and close $\left(14.3 \pm 0.8^{\circ}\right)$ targets

There was an effect of Target on the displacement of the center of the scapula relative to the trunk (Figure 4). This was significant for the lateral and vertical components and the 3D displacement $(F 72,8=36.1, F 72,8=20.7$ and $F 72,8=69.4$, respectively, $\mathrm{p}<0.0001)$.

There was a significant effect of Target on the final posture of the three DoF of GH (horizontal abduction F72,8=4.2, $\mathrm{p}<0.001$; elevation F72,8=263.7, $\mathrm{p}<0.0001$ and axial rotation $\mathrm{F} 72,8=8.7, \mathrm{p}<0.0001$ ). Horizontal abduction was mainly related to target direction (it was greater for internal than for external targets, except for close targets). Elevation was greater for high $\left(40.9 \pm 0.9^{\circ}\right)$ than for far $\left(31.2 \pm 1^{\circ}\right)$ and close $\left(17.1 \pm 1^{\circ}\right)$ targets. The upperarm was more externally rotated for high $\left(-74.7 \pm 2.1^{\circ}\right)$ and far targets $\left(-70.4 \pm 2.2^{\circ}\right)$ but less so for close targets $\left(-57.6 \pm 3.5^{\circ}\right)$.

\section{Coordination between GH and ST rotations}

The amount of global rotation of the HT, ST and GH joints varied with Target (Two factors ANOVA F72,8 $=155.2$, F72,8 $=275.0$ and F72,8 $=516.7$ respectively, $\mathrm{p}<0.0001$ ) but not Side.

The global angles of both ST and GH varied linearly with the global HT angle (Figure 5) with strong regression coefficients for all subjects ( $\mathrm{r}^{2}$ from 0.780 to $0.985, \mathrm{p}<0.0001$ ). Correlations were significantly stronger on the left side $(F 18,1=16.4, p<0.001)$.

The slopes of the linear regression lines were $0.76 \pm 0.01$ for GH and $0.33 \pm 0.01$ for ST (significant difference, $\mathrm{p}<0.0001$ ) with no effect of Side. The ratio between the slopes (slope 
for GH divided by the slope for ST) was $2.45 \pm 0.16$. The regression lines for GH crossed the axis of abscissas at zero $\left(0.95^{\circ} \pm 0.79\right.$, ns $)$, showing that $\mathrm{GH}$ rotation was at the origin of the HT rotation. The regression lines for ST crossed the axis of abscissa at $2.7^{\circ} \pm 1.3$ (different from zero, $\mathrm{p}<0.01$ ) showing that $\mathrm{ST}$ rotation began after $\mathrm{GH}$, but within a few degrees of HT rotation.

\section{PCA analysis: dimension of ST motion}

Three PCs explained a total $76.5 \%$ of the variance of the 6 DoF of ST motion. Correlations between DoF and PCs are shown in Table 3. The first PC (31.8\%) was correlated with internal rotation $(\mathrm{r}=0.717)$ and lateral $(\mathrm{r}=0.812)$ and anterior $(\mathrm{r}=0.735)$ displacement of the scapula center. The second PC (22.8\% of variance) was correlated with lateral rotation $(\mathrm{r}=0.883)$. The third PC $(21.9 \%$ of variance $)$ was negatively correlated with tilt $(r=-0.804)$ (i.e. correlated with anterior tilt) and correlated with the upward displacement of the scapula center $(\mathrm{r}=0.804)$.

\section{Contribution of the shoulder girdle to the workspace of the hand}

The contribution of the scapula to the extent of the workspace was evaluated by a direct kinematic procedure. We compared the measured 3D pointer displacement with that computed by our basic and reduced direct kinematic models. Figure 6 illustrates the mean displacement of the pointer, projected in the horizontal (A) and the frontal planes (B).

The models were compared two by two, due to numerical singularities when including 3 levels of the factor Model in the three factors ANOVA (Model, Side, Target).

The approximation of the basic model described in (Hanneton et al., 2011) was evaluated by comparison of the measured and computed pointer displacements (Figure 6, compare black and grey symbols). There was no effect of Side.

The contribution of ST rotations to the 3D displacement of the hand in space (for the same trunk and distal upper-limb joint rotations) was evaluated by comparison of pointer 
displacement computed by the basic and reduced kinematic models (Figure 6, compare grey and open symbols). There was a highly significant effect of Model (F72,8=425.6, F72,8=57.3 and $\mathrm{F} 72,8=151.9$ for the lateral, antero-posterior and vertical directions respectively, $\mathrm{p}<0.0001)$ and Target $(\mathrm{F} 72,8=1255, \mathrm{~F} 72,8=148.2$ and F72,8=556.0, respectively $\mathrm{p}<0.0001)$ and strong interactions between Target and Model (F72,8=274.6, F72,8=133.8 and F72,8 $=556.0, p<0.0001)$. There was no significant effect of Side. If no scapular rotation occurred, the workspace would be reduced by $15.8 \pm 2.4 \mathrm{~cm}$ laterally, $12 \pm 2.3 \mathrm{~cm}$ vertically and $4.1 \pm 1.2 \mathrm{~cm}$ anteriorly.

The difference between the measured and computed workspaces is summarized by the amount of 3D pointer displacement during the movement which varied from $10 \mathrm{~cm}$ for the Close-Middle target to $41 \mathrm{~cm}$ for the High-Internal Target (Figure 7). There was a highly significant effect of Model $(\mathrm{F} 72,8=322.9, \mathrm{p}<0.0001)$ and Target $(\mathrm{F} 72,8=532.8, \mathrm{p}<0.0001)$ and strong interactions between Target and Model (F72,8=145.4, $\mathrm{p}<0.0001)$. The amount of pointer displacement was smaller with the computed basic model than the measured displacement, and even smaller with the reduced model. The difference varied widely with the target: it was null for the Close-External target but attained $13.5 \pm 2.4 \mathrm{~cm}$ for the HighInternal target.

\section{DISCUSSION}

\section{Scapulo-thoracic motion contributes to pointing.}

This study analyzed motion of the shoulder girdle during pointing movements in the peripersonal space (i.e. a relatively wide 3D space within reach, similar to gestures carried out in daily life sitting at a table). The accuracy of pointing varied with the target but we considered that the relatively low level of error (less than $1.5 \mathrm{~cm}$ ) was tolerable in the framework of this study. The results confirmed that the clavicle and scapula (determining ST motion) are 
significant elements of the upper-limb kinematic chain. This was demonstrated by the facts that i) the initial and final postures of most ST DoF (scapular rotation and displacement of the scapula center, which both depend on clavicular motion) differed, and ii) most joint motion was consistently scaled to the 3D position of the target. Despite the restraining strap, the initial and final position of the trunk varied slightly during the experiment. However, this does not minimize the role of the shoulder complex since the motion of the scapula was calculated relative to the trunk. The present study thus demonstrates that the shoulder girdle contributed to the reaching movement of the hand. (It is highly likely that the elbow joint also contributed to the movement but not the distal joints that were immobilized in a splint).

\section{Coordination within the shoulder girdle}

We used two methods to analyze coordination within the shoulder girdle. The coordination between the clavicle and scapula was quantified by the dimension of ST motion obtained with PCA, and the coordination between the scapula and the humerus was quantified by the ratio between global GH to ST rotations.

First, the present study confirmed that the displacement of the scapula center and ST rotation, which both depend on motion at the sterno-clavicular and acromio-clavicular joints, are finely coordinated since 3 PCs explained the variance in the motion of the 6 ST DoF (Roren et al., 2015). Remarkably, this is similar to what we found for large amplitude movements (maximal elevation, voluntary shoulder roll and simulation of hair combing and back washing) in a previous study (Roren et al., 2015). This suggests that the DoF of the clavicle and scapula are associated in three elementary movement patterns: protraction (internal rotation and antero-lateral displacement), shrug (anterior tilt and upward displacement) and lateral rotation, which can be combined to induce different upper-limb movements. Such a description of ST motion, consistent with the model proposed by Seth et 
al. (Seth et al., 2015), could lead to functional and clinical indexes which would be easier to interpret than those of the ISB protocol.

Second, we proposed a new method to compute the ratio between GH and ST rotations. Previous studies have often quantified this coordination by calculating the ratio of GH elevation to ST lateral rotation during planar elevation tasks (Codman, 1934; Inman et al., 1996). The consideration of all the DOF of the shoulder girdle during unconstrained 3D movements complicates the definition of scapulo-humeral rhythm (Robert-Lachaine et al. 2015). The Euler angle formalism is also difficult to interpret (Michaud, Jackson, Prince, \& Begon, 2012). Using the global angle approach, we found that both ST and GH rotations were linearly related to the global rotation of the HT joint. Moreover, the regression lines passed near the origin, showing that ST motion began within the first degrees of HT motion. This contrasts with the common belief that ST motion mainly contributes to larger amplitude HT movements (Forte, de Castro, de Toledo, Ribeiro, \& Loss, 2009; McQuade \& Smidt, 1998; Scibek \& Carcia, 2012; Talkhani \& Kelly, 1997). This difference may be due to the direction of the studied movement (forward for reaching versus upward during elevation) and/or to the low sensitivity of the previously used clinical methods. The ratio of the slopes of the regression lines between the global GH and ST angles generalizes the notion of "scapulohumeral rhythm" to 3D space: we found a constant ratio of $2.4: 1$ confirming that the ST joint contributes around one third of HT motion (Inman et al., 1996).

\section{Contribution of ST motion to the extent of the hand workspace}

We estimated the functional impact of ST motion on the peri-personal workspace using a direct kinematic procedure. Our basic model is oversimplified since it lacks a clavicle (Hanneton et al., 2011). The difference between the computed and measured pointer displacements $(\sim 2 \mathrm{~cm})$ was in the same range as the measured displacement of the scapula center $(0.5$ to $2 \mathrm{~cm})$. This suggests that most of the difference between the computed and 
measured pointer displacements could be attributed to the lack of clavicle, consistently with our previous study on trunk assisted reaching (Hanneton et al., 2011). In addition, we compared the measured pointer displacement to that which would occur if there was no rotation at the ST joint (reduced model). Comparison of the output of the basic and reduced models demonstrated that 3D scapular rotations contributed significantly to the extent of the workspace. Finally, the comparison of the output of the reduced model with the measured hand displacement provides an overall estimation of the contribution of scapulo-thoracic motion (clavicle and scapula as a whole) to the workspace.

As expected, the contribution of ST motion to the workspace varied with the target: it was minimal for the external targets that were roughly in the resting plane of the scapula, but reached $\sim 15 \mathrm{~cm}$ in the upper-internal peri-personal space. This finding is not unexpected since it is well known that the shoulder girdle contributes to the mobility of the hand (Veeger \& van der Helm, 2007), however the present study is the first to precisely quantify this contribution. More surprisingly, we found that ST motion clearly contributed to the height of the hand above the table, even for low targets. Due to anatomical considerations, this effect is probably due to the reduction in anterior tilt during forward reaching movement, although its variation according to the target was not significant.

\section{Implications for motor control}

The results of this study clearly demonstrated that most DoF of the shoulder girdle (including the clavicle and scapula) were active and well-coordinated during movements.

The coupling between scapula rotation and the displacement of its center could either be the result of a synergic organization of movement by the central nervous system (Bernstein, 1967; Latash, 2008) or, more likely, of biomechanical constraints caused by the sliding of the scapula around the curved thoracic wall (Bolsterlee, Veeger, \& van der Helm, 2014; Seth et al., 2015). These hypotheses are not incompatible with each other since movement is shaped 
both by central neural networks and local biomechanical constraints (Schaal \& Sternad, 2001).

It is well known that the coordination between ST and GH is organized by synergies involved in pointing and reaching movements (Reisman \& Scholz, 2006; Tseng et al., 2002; Tseng et al., 2003; Yang et al., 2007). The present study is the first to demonstrate a fine tuning of the different elements of the shoulder girdle to the 3D position of the target and thus to the direction of hand movement. This is consistent with the hypothesis that motor control is based on reference joint postures (Desmurget \& Prablanc, 1997; Feldman, 1998; Rosenbaum et al., 2001). However, kinematic observations and direct modeling are insufficient to investigate the relationship between intended hand movement and upper-limb coordination. Our claim is that further studies on the control of inter-joint coordination of the upper-limb should include an analysis of ST motion as an integral part of the kinematic chain.

It is also important to consider ST motion in the study of the organization of muscle activity and cerebral control of upper-limb movements. The fact that ST motion began as soon as the first degrees of HT elevation occurred shows that all the muscles which attach to the clavicle and the scapula (i.e. all the thoracic muscles except the erector spinae and inconstantly latissimi dorsi) may be involved in even the smallest displacement of the hand. The fine scaling of internal and lateral scapula rotations to target position was continuous across the internal (involving more HT flexion) and external targets (involving more HT abduction). This suggests that the functional anatomy of the shoulder girdle muscles is more subtle than that usually described during planar elevation movements. In particular, we suggest that the activation of the muscles which reduce the anterior tilt, along with scapula lateral rotation during planar arm elevation (serratus anterior and the upper trapezius/lower trapezius force couple (Borstad \& Ludewig, 2005; McClure et al., 2001; Phadke, Camargo, \& 
Ludewig, 2009, review in Kibler et al., 2013)) is needed to prevent the hand from dropping during reaching movements.

\section{Implications for the clinical examination and rehabilitation of the shoulder.}

ST motion is commonly evaluated during clinical examinations of the shoulder (Watson, 2005). However quantitative measures (such as inclinometry) are imprecise and limited to the analysis of planar elevation. The present study could provide a basis for the development of new indexes for patho-physiological investigations of shoulder girdle function in the peripersonal workspace and/or during daily life activities (Aizawa et al., 2010; Roren et al., 2012). In orthopedics, many shoulder pathologies are associated with neuro-muscular disorders which induce changes in scapular posture and movement, termed dyskinesis (Kibler \& Sciascia, 2010). Scapula dyskinesis can also occur in the case of specific muscle paralysis (Roren et al., 2013). Altered activity of the serratus anterior and trapezius muscles could explain the impaired tilting observed in patients with shoulder impingement (Cools, Witvrouw, Declercq, Vanderstraeten, \& Cambier, 2004 ; Ludewig \& Reynolds, 2009; Phadke et al., 2009).

Conversely, abnormal scapula positioning due to poor functional habits may induce strain and lead to impingements, thus creating or exacerbating shoulder pathologies (Kibler et al., 2013). Dysfunction around the cervical spine may also impact shoulder function (Cools et al., 2014). These effects can be explained by the coupling between the upward motion of the center of the scapula and anterior tilt that we observed. If the scapula is shrugged due to a slouched posture or an excessive contraction of the trapezius muscle, the workspace of the hand would be globally tilted down imposing greater GH contribution for similar target height. Thus, it is important to characterize scapula dyskinesis using instrumental methods since it can be difficult to detect clinically and because it can be targeted by specific rehabilitation methods (Kibler et al., 2013). 
More generally, scapulo-thoracic motion enhances the large redundancy of the upper-limb for goal directed movements in space and thus the possibility of motor equivalence and compensation (Levin, Kleim, \& Wolf, 2009; Scholz \& Schoner, 2014). Our individualized direct kinematic procedure could be used to study the contribution of scapular motion to the workspace in shoulders with neurological or orthopedic pathology. This could lead to new and interesting clinical indexes to differentiate between impaired scapula motion (decreased contribution of the scapula to the workspace of the hand) and compensatory strategies (increased contribution of scapula to the workspace of the hand).

\section{Limitations}

The small number of middle-aged participants of both genders is a strong limitation of the present study. This is an exploratory, descriptive study that may encompass a variety of physiological situations but it is possible that some participants had sub-clinical shoulder pathology. Further studies should include larger groups of participants to define normative values of ST motion.

\section{Conclusions and perspectives}

In conclusion, the present study confirmed the hypothesis that scapula-thoracic motion largely contributes to the workspace of the hand: the range of motion of most of the studied DoF was relatively large and it was finely scaled to the spatial position of the targets. As expected, ST particularly contributed to hand movement in the high-internal part of the workspace and also maintained the hand above the table.

The physiology of shoulder motion should be further analyzed with EMG or other recording or imagery methods. This would allow the anatomo-functional roles of the thoracic muscles to be specified during medium-range hand movements.

This work could be continued by the development of functional indexes, based on the decomposition of ST motion into three elementary patterns, and on the direct kinematic 
analysis, which could be used in clinics or more generally in ergonomic or sports evaluations. A better quantitative knowledge of shoulder girdle function is important for the rehabilitation and prevention of shoulder pathologies.

\section{List of abbreviations}

DoF: Degree of freedom.

GH: glenohumeral joint

ST: Scapulo-thoracic joint

HT: Humero-thoracic rotations

PCA: Principal Component Analysis

PC(s): Principal Component(s)

\section{Competing interests}

The authors declare that they have no competing interests.

\section{Author's contributions}

ARB conceived the study, and drafted the manuscript JR participated in the design of the study, carried out the experiment and drafted the manuscript, AR participated in the interpretation of the data and drafted the manuscript, MMLC participated in the design and interpretation of the study. All authors read and approved the final manuscript.

\section{Acknowledgments}

This work was supported by the French National Agency for Research (ANR, Brahma project, PSIROB-ROBO-003). We thank Simon Bouvel, Guillaume Morel and Viviane Pasqui for fruitful discussions. 


\section{Appendices}

\section{Appendix 1: Geometrical center}

The coordinates of the center $\mathrm{G}$ of a triangle $\mathrm{ABC}$ are calculated as follow:

$x G=\frac{x A+x B+x C}{3} ; y G=\frac{y A+y B+y C}{3} ; z G=\frac{z A+z B+z C}{3}$

The computation is similar for the center of a four sided polygon.

\section{Appendix 2: Global rotation angle}

According to Euler's rotation theorem, any rotation or sequence of rotations of a rigid body in a three-dimensional space is equivalent to a pure rotation about a single fixed axis. Thus, a rotation in a three-dimensional Euclidean space can be represented by two values: a unit vector indicating the direction of the axis of rotation, and an angle $\theta$ describing the magnitude of the rotation about this axis. These values can be computed from the rotation matrixusingthe formulae below where $\mathrm{A}_{11}, \mathrm{~A}_{22}$ and $\mathrm{A}_{33}$ are the diagonal elements of the rotation matrix.

$$
\theta=\arccos \left(\frac{1}{2}\left[A_{11}+A_{22}+A_{33}-1\right]\right)
$$

\section{Appendix 3: Direct kinematic model.}

The trunk and upper-limb configuration is represented by a rigid body model consisting of a chain of 4 polygons (trunk, scapula, upper and lower arm) delimited by the 3D position of their bony landmarks in the global laboratory reference frame. Each segment is thus defined by (1) a set of anatomical reference points determining its shape, (2) a reference frame, and (3) the origin of the reference frame. The polygons are delimited by bony landmarks calibrated on each participant at rest. The position of the $i^{\text {th }}$ segment relative to $(i-1)^{\text {th }}$ is given by a sequence of three Euler angles and the coordinates of the origin of the segment reference frame in the reference frame of the $(i-1)^{\text {th }}$ segment. This model sets the origin of 
the trunk and scapula reference frames in their respective center. The model has no clavicle and assumes that CS has a fixed position relative to the thorax reference frame. The other local coordinate system definitions and Euler angle sequences of rotations are consistent with the ISB standardized protocol (van der Helm, 1997). The first step is to compute the time courses of the Euler angles between rigid bodies (van der Helm, 1997) during the movement. The direct kinematic procedure consists of the computation of the 3D movement of the body landmarks based on their initial positions (measured at rest for each individual) and the time course of the rotations in all the DoF of the model. This procedure can simulate the theoretical 3D position of any body-landmark at any time during the movement. In a previous study, based on trunk assisted reaching movements, we quantified the differences between the computed and the measured movement of the endpoint which resulted from the approximations of the model (Hanneton et al., 2011). In particular, we demonstrated that approximations in the model at shoulder level, could account for $\sim 4 \mathrm{~cm}$ of hand displacement.

The individualized direct kinematic model can be fed by a modified sequence of rotations applied to the DoFs of the chain. In particular, the level of rotation of any DoF can be kept constant during the simulated movement, allowing quantifying the contribution of this particular DoF to the movement of the endpoint, independently of all the other, non altered, rotations. 


\section{Figure legends}

\section{Figure 1: Experimental set-up}

A: Horizontal arrangement of the far and close targets on the table. B: Vertical arrangement of the high targets at the far distance. C: Wrist splint and pointer.

\section{Figure 2: Characterization of shoulder girdle rotations.}

A: Schema for the definition of body landmarks and axes of rotation. The thorax is represented by the quadrilateral limited by: processus spinosous of $\mathrm{C} 7$ and $\mathrm{T} 8$ vertebrae, incisura jugularis and processus xiphoideus (on the ventral side, not indicated). The scapula is represented by the triangle limited by: angulus acromialis (AA), angulus inferior (AI) and trigonum scapulae (TS), its center is indicated by the square. The humerus is represented by a triangle limited by the center of the gleno-humeral joint $(\mathrm{GH})$ and the medial and lateral epicondylus (ME, LE). For clarity, the reference frame of the thorax is indicated at the bottom of the schema. The orientation of the scapula relative to the trunk (ST) is expressed by three ordered Euler angles internal-external rotation around the trunk Y axis, medial-lateral rotation around the $\mathrm{Z}$ axis of the scapula (perpendicular to the plane formed by AA-AI-TS, pointing backwards) and antero-posterior tilt around the $\mathrm{X}$ axis of the scapula (along scapular spine). The orientations of the upper-arm relative to the scapula (gleno-humeral joint, GH) and relative to the trunk (humero-thoracic joint, HT) are expressed by three ordered Euler angles: horizontal abduction around the $\mathrm{Y}$ axis of the scapula (or trunk), elevation around the $\mathrm{Z}$ axis (perpendicular to the plane formed by GH-ME-LE, pointing backwards) and axial rotation around the $\mathrm{Y}$ axis of the humerus.

B: Example of scapulo-thoracic rotations during pointing and return movements to the nine targets indicated in the legend. Each line represents one movement made by a representative subject. Higher positive values indicate: ST internal and lateral rotations and posterior tilt. 
C: Humero-thoracic elevation recorded during the same movements.

Figure 3: Comparison of initial and final trunk and shoulder postures for each target.

The graph shows the range of motion in the three Euler angles which describe the orientation of the Trunk and Scapulo-thoracic joint (ST) and elevation in the Gleno-humeral (GH) joints. The initial values are indicated by thick lines. For the sake of clarity, only the results for the right side are displayed. The directions (Int: internal, Mid: middle, Ext external) and the distances (High, Far, Close) of the targets are indicated on the abscissa. Each bar represents the mean (and SEM) of the 10 subjects. The trunk is vertical at $90^{\circ}$ (greater values indicating extension), positive values indicate left trunk bending and left axial rotation. Higher positive values indicate ST internal and lateral rotations and posterior tilt, GH elevation.

\section{Figure 4: 3D displacement of the center of the scapula.}

CS is the geometrical center of the scapula relative to the thorax. The targets are indicated as in Figure 2. Each bar represents the mean (and SEM) of the right side in the 10 subjects.

\section{Figure 5: Scapulo-humeral rhythm}

Amount of global rotation in GH (triangles) and ST (circles) as a function of global HT rotation (black symbols represent the right side, open symbols the left side). Each symbol represents the data for one target reached by one hand of one subject. The regression lines are indicated for the right (full line) and left sides (stippled line).

Figure 6: Direct kinematic analysis: projection of the final position of the pointer in space.

A: horizontal projection (the far and high targets appear superimposed); B: frontal projection (the far and close targets appear superimposed). Each point represents the 3D position of the pointer in space, relative to the initial position: black symbols represent the measured position; grey symbols the output of the basic direct model; open symbols the 
output of the reduced model without scapular rotation. Each point represents the mean (and SEM) of the right side of the 10 subjects.

Figure 7: Direct kinematic analysis: global displacement of the pointer.

The black symbols indicate the measured displacement; the grey symbols the output of the basic direct computation and the open symbols the output of the reduced model without scapula rotation. Each symbol represents the mean (and SEM) of the right side in the 10 subjects. 


\section{REFERENCES}

Aizawa, J., Masuda, T., Koyama, T., Nakamaru, K., Isozaki, K., Okawa, A. (2010). Threedimensional motion of the upper extremity joints during various activities of daily living. $J$ Biomech, 43(15), 2915-2922.

Bernstein, N. (1967). The co-ordination and regulation of movements. Oxford: Pergamon.

Bernstein, N. (1967). The coordination and regulation of movements. New York: Pergamon Press.

Biryukova, E. V., Roby-Brami, A., Frolov, A. A., \& Mokhtari, M. (2000). Kinematics of human arm reconstructed from spatial tracking system recordings. J Biomech, 33(8), 985-995.

Bolsterlee, B., Veeger, H. E., \& van der Helm, F. C. (2014). Modelling clavicular and scapular kinematics: from measurement to simulation. Med Biol Eng Comput, 52(3), 283-291.

Borstad, J. D., \& Ludewig, P. M. (2005). The effect of long versus short pectoralis minor resting length on scapular kinematics in healthy individuals. J Orthop Sports Phys Ther, 35(4), 227-238.

Codman, M. (1934 ). The Shoulder Boston: : Thomas Todd Co.

Cools, A. M., Struyf, F., De Mey, K., Maenhout, A., Castelein, B., \& Cagnie, B. (2014). Rehabilitation of scapular dyskinesis: from the office worker to the elite overhead athlete. $\mathrm{Br}$ J Sports Med, 48(8), 692-697.

Cools, A. M., Witvrouw, E. E., Declercq, G. A., Vanderstraeten, G. G., \& Cambier, D. C. (2004). Evaluation of isokinetic force production and associated muscle activity in the scapular rotators during a protraction-retraction movement in overhead athletes with impingement symptoms. Br J Sports Med, 38(1), 64-68. 
Desmurget, M., \& Prablanc, C. (1997). Postural control of three-dimensional prehension movements. Journal of Neurophysiology, 77, 452-464.

Desmurget, M., Prablanc, C., Rossetti, Y., Arzi, M., Paulignan, Y., Urquizar, C. (1995). Postural and synergic control for three-dimensional movements of reaching and grasping. Journal of Neurophysiology, 74(2), 905-910.

Fayad, F., Hoffmann, G., Hanneton, S., Yazbeck, C., Lefevre-Colau, M. M., Poiraudeau, S. (2006). 3-D scapular kinematics during arm elevation: effect of motion velocity. Clin Biomech (Bristol, Avon), 21(9), 932-941.

Feldman, A. G. (1998). Spatial frames of reference for motor control. In L. M.L. (Ed.), Progress in Motor control, Vol one (pp. 289-313): Human kinetics.

Forte, F. C., de Castro, M. P., de Toledo, J. M., Ribeiro, D. C., \& Loss, J. F. (2009). Scapular kinematics and scapulohumeral rhythm during resisted shoulder abduction-implications for clinical practice. Phys Ther Sport, 10(3), 105-111.

Gielen, C. C., Vrijenhoek, E. J., Flash, T., \& Neggers, S. F. (1997). Arm position constraints during pointing and reaching in 3-D space. J Neurophysiol, 78(2), 660-673.

Giphart, J., Brunkhorst, J., Horn, N., Shelburne, K., Torry, M., \& Millett, P. (2013). Effect of plane of arm elevation on glenohumeral kinematics: a normative biplane fluoroscopy study. J Bone Joint Surg Am, 95(3), 238-245.

Hanneton, S., Dedobbeler, S., Hoellinger, T., \& Roby-Brami, A. (2011). Direct kinematic modeling of the upper limb during trunk-assisted reaching. J Appl Biomech, 27(3), 272-277.

Inman, V. T., Saunders, J. B., \& Abbott, L. C. (1996). Observations of the function of the shoulder joint. 1944. Clin Orthop Relat Res(330), 3-12.

Kapandji, I. A. (1980). Physiologie articulaire. Tome 1, membre supérieur. (Vol. 1). Paris: Maloine. 
Kibler, W. B., Ludewig, P. M., McClure, P. W., Michener, L. A., Bak, K., \& Sciascia, A. D. (2013). Clinical implications of scapular dyskinesis in shoulder injury: the 2013 consensus statement from the 'Scapular Summit'. Br J Sports Med, 47(14), 877-885.

Kibler, W. B., \& Sciascia, A. (2010). Current concepts: scapular dyskinesis. Br J Sports Med, 44(5), 300-305.

Latash, M. L. (2008). Synergy. New York: Oxford university press.

Lawrence, R. L., Braman, J. P., Staker, J. L., Laprade, R. F., \& Ludewig, P. M. (2014). Comparison of 3-dimensional shoulder complex kinematics in individuals with and without shoulder pain, part 2: glenohumeral joint. J Orthop Sports Phys Ther, 44(9), 646-655, B641643.

Lempereur, M., Brochard, S., Leboeuf, F., \& Remy-Neris, O. (2014). Validity and reliability of 3D marker based scapular motion analysis: a systematic review. J Biomech, 47(10), 2219-2230.

Lenarcic, J., \& Stanisic, M. (2003). A Humanoid Shoulder Complex and the Humeral Pointing Kinematics. , Vol. 19, N. 3, pp. 499-506. IEEE Transactions on Robotics and Automation, 19(3), 499-506.

Levin, M. F., Kleim, J. A., \& Wolf, S. L. (2009). What do motor "recovery" and "compensation" mean in patients following stroke? Neurorehabil Neural Repair, 23(4), 313319.

Ludewig, P., Phadke, V., Braman, J., Hassett, D., Cieminski, C., \& Laprade, R. (2009). Motion of the shoulder complex during multiplanar humeral elevation. J Bone Joint Surg Am, 91(2), 378-389.

Ludewig, P. M., Behrens, S. A., Meyer, S. M., Spoden, S. M., \& Wilson, L. A. (2004). Three-dimensional clavicular motion during arm elevation: reliability and descriptive data. $J$ Orthop Sports Phys Ther, 34(3), 140-149. 
Ludewig, P. M., Cook, T. M., \& Nawoczenski, D. A. (1996). Three-dimensional scapular orientation and muscle activity at selected positions of humeral elevation. J Orthop Sports Phys Ther, 24(2), 57-65.

Ludewig, P. M., \& Reynolds, J. F. (2009). The association of scapular kinematics and glenohumeral joint pathologies. J Orthop Sports Phys Ther, 39(2), 90-104.

Magermans, D. J., Chadwick, E. K., Veeger, H. E., \& van der Helm, F. C. (2005). Requirements for upper extremity motions during activities of daily living. Clin Biomech (Bristol, Avon), 20(6), 591-599.

McClure, P. W., Michener, L. A., Sennett, B. J., \& Karduna, A. R. (2001). Direct 3dimensional measurement of scapular kinematics during dynamic movements in vivo. $J$ Shoulder Elbow Surg, 10(3), 269-277.

McQuade, K. J., \& Smidt, G. L. (1998). Dynamic scapulohumeral rhythm: the effects of external resistance during elevation of the arm in the scapular plane. J Orthop Sports Phys Ther, 27(2), 125-133.

Medendorp, W. P., Crawford, J. D., Henriques, D. Y., Van Gisbergen, J. A., \& Gielen, C. C. (2000). Kinematic strategies for upper arm-forearm coordination in three dimensions. $J$ Neurophysiol, 84(5), 2302-2316.

Michaud, B., Jackson, M. I., Prince, F., \& Begon, M. S. (2012). Can one angle be simply subtracted from another to determine range of motion in three-dimensional motion analysis? Comput Methods Biomech Biomed Engin, 17(5), 507-515.

Nishikawa, K. C., Murray, S. T., \& Flanders, M. (1999). Do arm postures vary with the speed of reaching? J Neurophysiol, 81(5), 2582-2586.

Phadke, V., Camargo, P., \& Ludewig, P. (2009). Scapular and rotator cuff muscle activity during arm elevation: A review of normal function and alterations with shoulder impingement. Rev Bras Fisioter, 13(1), 1-9. 
Pronk, G. M., van der Helm, F., \& Rozendaal, L. (1993). Interaction between the joints in the shoulder mechanism: the function of the costoclavicular, conoid and trapezoidligaments. . Paper presented at the Proceedings of the Institution of Mechanical Engineers. Part H, .

Reisman, D. S., \& Scholz, J. P. (2006). Workspace location influences joint coordination during reaching in post-stroke hemiparesis. Exp Brain Res, 170(2), 265-276.

Robert-Lachaine, X., Marion, P., Godbout, V., Bleau, J., \& Begon, M. (2015). Elucidating the scapulo-humeral rhythm calculation: 3D joint contribution method. Comput Methods Biomech Biomed Engin, 18(3), 249-258.

Robertson, J. V., Roche, N., \& Roby-Brami, A. (2012). Influence of the side of brain damage on postural upper-limb control including the scapula in stroke patients. Exp Brain Res, 218(1), 141-155.

Roren, A., Fayad, F., Poiraudeau, S., Fermanian, J., Revel, M., Dumitrache, A. (2013). Specific scapular kinematic patterns to differentiate two forms of dynamic scapular winging. Clin Biomech (Bristol, Avon), 28(8), 941-947.

Roren, A., Lefevre-Colau, M. M., Poiraudeau, S., Fayad, F., Pasqui, V., \& Roby-Brami, A. (2015). A new description of scapulothoracic motion during arm movements in healthy subjects. Man Ther, 20(1), 46-55.

Roren, A., Lefevre-Colau, M. M., Roby-Brami, A., Revel, M., Fermanian, J., Gautheron, V. (2012). Modified 3D scapular kinematic patterns for activities of daily living in painful shoulders with restricted mobility: a comparison with contralateral unaffected shoulders. $J$ Biomech, 45(7), 1305-1311.

Rosenbaum, D. A., Meulenbroek, R. G., Vaughan, J., \& Jansen, C. (1999). Coordination of reaching and grasping by capitalizing on obstacle avoidance and other constraints. Exp Brain Res, 128(1-2), 92-100. 
Rosenbaum, D. A., Meulenbroek, R. J., Vaughan, J., \& Jansen, C. (2001). Posture-based motion planning: applications to grasping. Psychol Rev, 108(4), 709-734.

Schaal, S., \& Sternad, D. (2001). Origins and violations of the $2 / 3$ power law in rhythmic three-dimensional arm movements. Exp Brain Res, 136(1), 60-72.

Scholz, J. P., \& Schoner, G. (2014). Use of the Uncontrolled Manifold (UCM) Approach to Understand Motor Variability, Motor Equivalence, and Self-motion. Adv Exp Med Biol, $826,91-100$.

Scibek, J. S., \& Carcia, C. R. (2012). Assessment of scapulohumeral rhythm for scapular plane shoulder elevation using a modified digital inclinometer. World J Orthop, 3(6), 87-94.

Seminati, E., Marzari, A., Vacondio, O., \& Minetti, A. E. (2015). Shoulder 3D range of motion and humerus rotation in two volleyball spike techniques: injury prevention and performance. Sports Biomech, 14(2), 216-231.

Seth, A., Matias, R., Veloso, A. P., \& Delp, S. L. (2015). A biomechanical model of the scapulothoracic joint to accurately capture scapular kinematics during shoulder movements. PLoS One, 11(1), e0141028.

Soechting, J. F., Buneo, C. A., Herrmann, U., \& Flanders, M. (1995). Moving effortlessly in three dimensions: does Donders' law apply to arm movement? The Journal of Neuroscience, 15(9), 6271-6280.

Talkhani, I. S., \& Kelly, C. P. (1997). Scapulothoracic rhythm in normal male volunteers. Biomed Sci Instrum, 34, 327-331.

Tseng, Y., Scholz, J. P., \& Schoner, G. (2002). Goal-equivalent joint coordination in pointing: affect of vision and arm dominance. Motor Control, 6(2), 183-207.

Tseng, Y. W., Scholz, J. P., Schöner, G., \& Hotchkiss, L. (2003). Effect of accuracy constraint on joint coordination during pointing movements. Experimental Brain Research, 149, 276-288. 
van der Helm, F. C., \& Pronk, G. M. (1995). Three-dimensional recording and description of motions of the shoulder mechanism. J Biomech Eng, 117(1), 27-40.

van der Helm, F. C. T. (1997). A standardized protocol for motion recordings of the shoulder. Paper presented at the Proceedings of the First Conference of the ISG, Delft.

van der Steen, M. M., \& Bongers, R. M. (2011). Joint angle variability and co-variation in a reaching with a rod task. Exp Brain Res, 208(3), 411-422.

Veeger, H. E., \& van der Helm, F. C. (2007). Shoulder function: The perfect compromise between mobility and stability. J Biomech, 40(10), 2119-2129.

Watson, L. (2005). General Assessment of the shoulder. Shoulderphysio (Ed.) CD Rom Retrieved from http://www.lynwatsonshoulderphysio.com.au/.

Yang, J. F., Scholz, J. P., \& Latash, M. L. (2007). The role of kinematic redundancy in adaptation of reaching. Exp Brain Res, 176(1), 54-69.

Zatsiorsky, V. M. (2002). Kinetics of human motion. Champaign, IL: Human Kinetics. 
Table 1 : Statistical analysis of the kinematic variables of the trunk and shoulder during the pointing movements.

Results of the three factors ANOVA (Range, Side and Target): the table shows the $F$ and $p$ value for each DoF, ns: not significant.

A: Orientation of the trunk, scapulo-thoracic (ST) and gleno-humeral (GH) joints.

\begin{tabular}{|c|c|c|c|c|c|c|}
\hline DoF & Range & Side & Target & $\begin{array}{c}\text { Range } x \\
\text { side }\end{array}$ & $\begin{array}{c}\text { Range } x \\
\text { Target }\end{array}$ & $\begin{array}{c}\text { Target x } \\
\text { Side }\end{array}$ \\
\hline Trunk & F72,1=56.4 & & $F 72,8=6.3$ & & $F 72,8=18.6$ & \\
\hline flexion extension & $<.0001$ & ns & $<.0001$ & ns & $<.0001$ & $\mathrm{~ns}$ \\
\hline $\begin{array}{c}\text { Trunk } \\
\text { lateral bending }\end{array}$ & ns & ns & ns & ns & ns & ns \\
\hline Trunk & F72,1=39.4 & & $F 72,8=11.6$ & & $F 72,8=33.7$ & \\
\hline axial rotation & 0.0001 & ns & $<.0001$ & ns & $<.0001$ & ns \\
\hline $\begin{array}{c}\text { ST internal- } \\
\text { external rotation }\end{array}$ & $\begin{array}{c}\mathrm{F} 72,1=360.8 \\
<.0001\end{array}$ & ns & $\begin{array}{c}\mathrm{F} 72,1=56.0 \\
<.0001\end{array}$ & ns & $\begin{array}{c}\mathrm{F} 72,8=110.2 \\
<.0001\end{array}$ & ns \\
\hline $\begin{array}{c}\text { ST medial-lateral } \\
\text { rotation }\end{array}$ & $\begin{array}{c}F 72,1=167.2 \\
0.001\end{array}$ & ns & $\begin{array}{c}\mathrm{F} 72,1=58.5 \\
<.0001\end{array}$ & ns & $\begin{array}{c}\mathrm{F} 72,8=128.1 \\
<.0001\end{array}$ & ns \\
\hline $\begin{array}{l}\text { ST antero- } \\
\text { posterior tilt }\end{array}$ & ns & ns & ns & ns & ns & ns \\
\hline $\begin{array}{c}\text { GH } \\
\text { elevation }\end{array}$ & $\begin{array}{c}\mathrm{F} 72,1=204.7 \\
<.0001\end{array}$ & ns & $\begin{array}{c}F 72,1=206.3 \\
<.0001\end{array}$ & ns & $\begin{array}{c}\mathrm{F} 72,8=202.2 \\
<.0001\end{array}$ & ns \\
\hline
\end{tabular}

B: Position of the center of the scapula relative to the trunk.

\begin{tabular}{|c|c|c|c|c|c|c|}
\hline DoF & Range & Side & Target & $\begin{array}{c}\text { Range } x \\
\text { side }\end{array}$ & $\begin{array}{c}\text { Range x } \\
\text { Target }\end{array}$ & $\begin{array}{c}\text { Target x } \\
\text { Side }\end{array}$ \\
\hline \multirow[t]{2}{*}{ lateral } & $F 72,1=148.9$ & & $F 72,8=21$ & & $F 72,8=36.1$ & \\
\hline & $<0.0001$ & ns & $<.0001$ & ns & $<.0001$ & ns \\
\hline \multirow[t]{2}{*}{ vertical } & & & $F 72,8=6.9$ & & $F 72,8=20.7$ & \\
\hline & ns & ns & $<.0001$ & ns & $<.0001$ & ns \\
\hline \multicolumn{7}{|c|}{ antero-posterior } \\
\hline & ns & ns & ns & ns & ns & ns \\
\hline \multirow[t]{2}{*}{ 3D } & $F 72,1=141.6$ & & $F 72,8=14.6$ & & $F 72,8=20.5$ & \\
\hline & $<0.0001$ & ns & $<.0001$ & ns & $<.0001$ & ns \\
\hline
\end{tabular}


Table 2. Final configuration of the shoulder girdle for each target.

Each panel represents one DoF (right and left) of the scapulo-thoracic (ST) and gleno-humeral (GH) jolnts and the displacement of the centre of the scapula (CS). The stars indicate significant differences from the initial configuration except for the first and third $\mathrm{GH}$ angles since some initial values were missing $(* * *<0.0001 ; * *<0.001)$.

\begin{tabular}{|c|c|c|c|c|c|c|c|c|c|c|c|c|c|c|c|}
\hline \multirow[t]{2}{*}{ Targets } & \multicolumn{5}{|c|}{ ST (degrees) } & \multicolumn{5}{|c|}{ GH (degrees) } & \multicolumn{5}{|c|}{ CS displacement $(\mathrm{cm})$} \\
\hline & & Right & & Left & & & Right & & Left & & & Right & & Left & \\
\hline High-External & \multirow{9}{*}{ 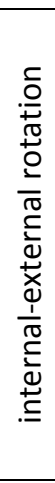 } & $36.87+1.88$ & $* * *$ & $42.20+2.51$ & $* * *$ & \multirow{9}{*}{ 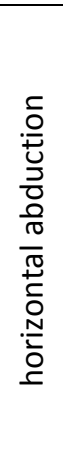 } & $23.94+3.86$ & & $15.59+2.97$ & & \multirow{9}{*}{$\begin{array}{l}\bar{\pi} \\
\frac{\pi}{\pi} \\
\frac{\pi}{\pi}\end{array}$} & $0.51+0.13$ & ns & $0.65+0.19$ & $* *$ \\
\hline High-Middle & & $43.35+1.99$ & $* * *$ & $47.28+2.20$ & $* * *$ & & $31.68+2.56$ & & $28.08+2.66$ & & & $1.27+0.17$ & $* * *$ & $1.28+0.14$ & $* * *$ \\
\hline High-Internal & & $45.66+2.01$ & $* * *$ & $49.65+2.60$ & $* * *$ & & $37.95+2.59$ & & $34.95+3.63$ & & & $1.51+0.20$ & $* * *$ & $1.42+0.19$ & $* * *$ \\
\hline Far-External & & $36.67+1.80$ & $* * *$ & $41.07+1.98$ & $* * *$ & & $25.42+4.33$ & & $20.78+2.98$ & & & $0.53+0.07$ & $* * *$ & $0.61+0.12$ & $* *$ \\
\hline Far-Middle & & $41.88+1.78$ & $* * *$ & $45.99+2.18$ & $* * *$ & & $36.24+3.98$ & & $32.71+3.27$ & & & $1.37+0.12$ & $* * *$ & $1.28+0.15$ & $* * *$ \\
\hline Far-Internal & & $43.89+1.70$ & $* * *$ & $46.62+2.25$ & $* * *$ & & $40.69+5.59$ & & $38.57+5.02$ & & & $1.70+0.18$ & $* * *$ & $1.45+0.22$ & $* * *$ \\
\hline Close-External & & $34.06+1.87$ & $* * *$ & $38.71+2.23$ & $* * *$ & & $26.51+12.53$ & & $27.99+5.84$ & & & $0.27+0.06$ & $* *$ & $0.34+0.12$ & ns \\
\hline Close-Middle & & $35.94+1.68$ & $* * *$ & $40.58+1.88$ & $* * *$ & & $32.11+6.34$ & & $26.09+7.00$ & & & $0.60+0.08$ & $* * *$ & $0.58+0.09$ & $* *$ \\
\hline Close-Internal & & $36.46+1.80$ & $* * *$ & $40.90+1.86$ & $* * *$ & & $17.15+5.36$ & & $21.19+7.37$ & & & $0.41+0.06$ & $* * *$ & $0.41+0.11$ & $\mathrm{~ns}$ \\
\hline High-External & \multirow{9}{*}{ 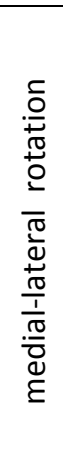 } & $18.99+1.84$ & $* * *$ & $23.56+2.84$ & $* * *$ & \multirow{9}{*}{$\begin{array}{l}\frac{c}{0} \\
\stackrel{0}{0} \\
\frac{0}{0} \\
\frac{0}{d}\end{array}$} & $38.93+2.13$ & $* * *$ & $35.38+2.57$ & $* * *$ & \multirow{9}{*}{ 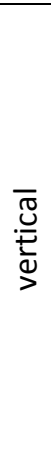 } & $-0.25+0.20$ & ns & $-0.08+0.12$ & $\mathrm{~ns}$ \\
\hline High-Middle & & $20.80+1.52$ & $* * *$ & $25.09+2.77$ & $* * *$ & & $45.17+1.95$ & $* * *$ & $42.48+2.40$ & $* * *$ & & $0.51+0.19$ & ns & $0.34+0.17$ & ns \\
\hline High-Internal & & $22.70+1.59$ & $* * *$ & $26.57+2.69$ & $* * *$ & & $43.29+1.83$ & $* * *$ & $40.59+1.98$ & $* * *$ & & $0.25+0.22$ & ns & $0.20+0.22$ & ns \\
\hline Far-External & & $14.14+1.68$ & $* * *$ & $16.79+2.47$ & $* * *$ & & $29.22+2.12$ & $* * *$ & $27.94+2.72$ & $* * *$ & & $0.16+0.10$ & ns & $0.16+0.10$ & ns \\
\hline Far-Middle & & $16.40+1.81$ & $* * *$ & $19.51+2.38$ & $* * *$ & & $35.49+2.23$ & $* * *$ & $32.86+2.48$ & $* * *$ & & $0.80+0.12$ & $* * *$ & $0.84+0.17$ & $* *$ \\
\hline Far-Internal & & $15.60+1.85$ & $* * *$ & $19.76+2.47$ & $* * *$ & & $32.32+1.99$ & $* * *$ & $29.38+2.47$ & $* * *$ & & $0.73+0.15$ & $* *$ & $1.03+0.17$ & $* *$ \\
\hline Close-External & & $12.17+1.67$ & $* * *$ & $15.12+2.41$ & $* *$ & & $14.12+1.84$ & $* * *$ & $12.16+2.57$ & ns & & $-0.14+0.08$ & ns & $-0.05+0.08$ & ns \\
\hline Close-Middle & & $12.78+1.91$ & $* * *$ & $16.27+2.33$ & $* * *$ & & $18.88+2.31$ & $* * *$ & $16.80+2.56$ & $* *$ & & $0.13+0.12$ & ns & $0.39+0.11$ & $*$ \\
\hline Close-Internal & & $13.20+1.48$ & $* * *$ & $15.98+2.41$ & $* * *$ & & $20.93+2.07$ & $* * *$ & $20.14+3.15$ & $* *$ & & $0.06+0.08$ & ns & $0.08+0.11$ & ns \\
\hline High-External & \multirow{9}{*}{ 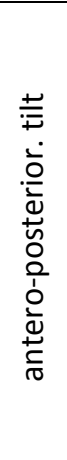 } & $-6.19+2.20$ & $\mathrm{~ns}$ & $-8.29+1.31$ & $* *$ & \multirow{9}{*}{ 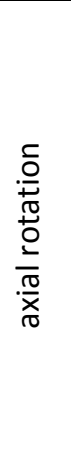 } & $-70.23+4.60$ & & $-74.40+6.14$ & & \multirow{9}{*}{ 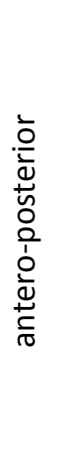 } & $0.15+0.14$ & ns & $0.38+0.23$ & $\mathrm{~ns}$ \\
\hline High-Middle & & $-6.38+2.34$ & $\mathrm{~ns}$ & $-7.82+1.54$ & $* *$ & & $-72.71+4.42$ & & $-79.77+5.03$ & & & $0.18+0.21$ & ns & $0.16+0.21$ & ns \\
\hline High-Internal & & $-8.34+2.57$ & $\mathrm{~ns}$ & $-8.67+1.64$ & $* *$ & & $-71.06+5.10$ & & $-80.01+6.76$ & & & $0.50+0.31$ & ns & $0.37+0.25$ & $\mathrm{~ns}$ \\
\hline Far-External & & $-6.57+2.37$ & ns & $-8.40+1.05$ & $* * *$ & & $-65.20+5.11$ & & $-72.04+4.87$ & & & $-0.06+0.06$ & ns & $-0.03+0.08$ & ns \\
\hline Far-Middle & & $-6.72+2.33$ & $\mathrm{~ns}$ & $-7.07+1.47$ & $* *$ & & $-69.64+5.06$ & & $-76.98+5.21$ & & & $-0.13+0.24$ & ns & $-0.07+0.13$ & ns \\
\hline Far-Internal & & $-6.45+2.16$ & $\mathrm{~ns}$ & $-6.06+1.87$ & $\mathrm{~ns}$ & & $-64.60+6.01$ & & $-73.90+7.02$ & & & $-0.11+0.25$ & ns & $0.03+0.24$ & ns \\
\hline Close-External & & $-8.25+2.55$ & $\mathrm{~ns}$ & $-10.03+0.92$ & $* * *$ & & $-57.37+11.36$ & & $-69.57+7.72$ & & & $0.10+0.06$ & ns & $0.25+0.08$ & ns \\
\hline Close-Middle & & $-6.70+2.15$ & ns & $-7.73+1.21$ & $* *$ & & $-56.64+6.55$ & & $-62.61+8.84$ & & & $-0.04+0.05$ & ns & $0.16+0.13$ & ns \\
\hline Close-Internal & & $-5.92+2.37$ & ns & $-7.68+1.14$ & $* * *$ & & $-43.95+7.06$ & & $-56.68+9.05$ & & & $-0.14+0.10$ & ns & $0.00+0.15$ & ns \\
\hline
\end{tabular}


Table 3: Principal component analysis, correlation between DoF and PCs.

Bold characters indicate significant correlations.

$\begin{array}{llll} & \text { Factor } \mathbf{1} & \text { Factor } \mathbf{2} & \text { Factor } \mathbf{3} \\ \text { ST Internal-external rotation } & \mathbf{0 . 7 1 7} & 0.336 & 0.36 \\ \text { ST medio-lateral rotation } & 0.153 & \mathbf{0 . 8 8 3} & <0.01 \\ \text { ST antero-posterior tilt } & -0.104 & 0.366 & -\mathbf{0 . 8 2 8} \\ \text { lateral displacement } & \mathbf{0 . 8 1 2} & 0.22 & -0.06 \\ \text { vertical displacement } & <0.01 & 0.42 & \mathbf{0 . 8 0 4} \\ \text { antero-posterior displacement } & \mathbf{0 . 7 3 5} & -0.402 & <0.01\end{array}$


Figure 1: Experimental set-up

A: Horizontal arrangement of the far and close targets on the table. B: Vertical arrangement of the high targets at the far distance. C: Wrist splint and pointer.

A: Horizontal target arrangement $\quad B$ : Vertical target arrangement $\quad C$ : Pointer

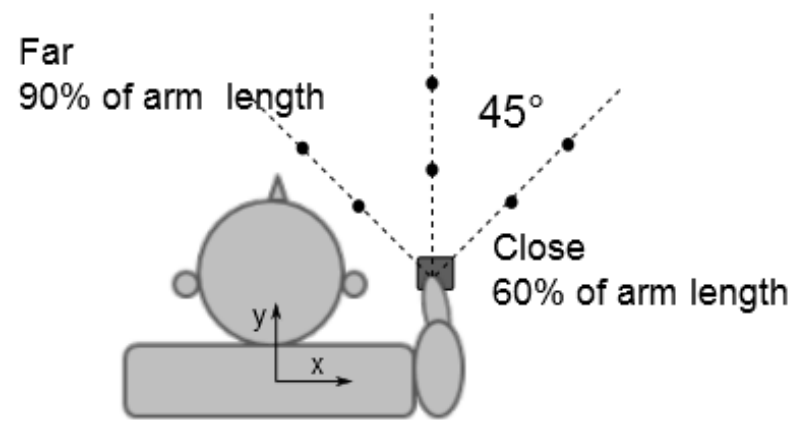

Shoulder height

(far)

$7 \mathrm{~cm}$ above table

(far or close)

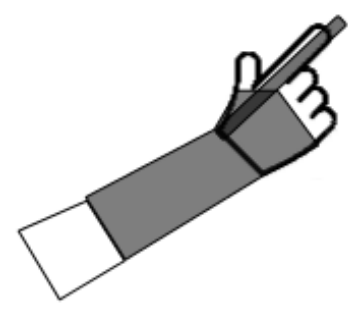


Figure 2: Characterization of shoulder girdle rotations.

A: Schema for the definition of body landmarks and axes of rotation. The thorax is represented by the quadrilateral limited by: processus spinosous of $\mathrm{C} 7$ and $\mathrm{T} 8$ vertebrae, incisura jugularis and processus xiphoideus (on the ventral side, not indicated). The scapula is represented by the triangle limited by: angulus acromialis (AA), angulus inferior (AI) and trigonum scapulae (TS), its center is indicated by the square. The humerus is represented by a triangle limited by the center of the gleno-humeral joint $(\mathrm{GH})$ and the medial and lateral epicondylus (ME, LE). For clarity, the reference frame of the thorax is indicated at the bottom of the schema. The orientation of the scapula relative to the trunk (ST) is expressed by three ordered Euler angles internal-external rotation around the trunk $\mathrm{Y}$ axis, medial-lateral rotation around the $\mathrm{Z}$ axis of the scapula (perpendicular to the plane formed by AA-AI-TS, pointing backwards) and antero-posterior tilt around the $\mathrm{X}$ axis of the scapula (along scapular spine). The orientations of the upper-arm relative to the scapula (gleno-humeral joint, GH) and relative to the trunk (humero-thoracic joint, HT) are expressed by three ordered Euler angles: horizontal abduction around the $\mathrm{Y}$ axis of the scapula (or trunk), elevation around the $\mathrm{Z}$ axis (perpendicular to the plane formed by GH-ME-LE, pointing backwards) and axial rotation around the $\mathrm{Y}$ axis of the humerus.

B: Example of scapulo-thoracic rotations during pointing and return movements to the nine targets indicated in the legend. Each line represents one movement made by a representative subject. Higher positive values indicate: ST internal and lateral rotations and posterior tilt.

$\mathrm{C}$ : Humero-thoracic elevation recorded during the same movements.

A

\section{B:Scapulo-thoracic rotations}
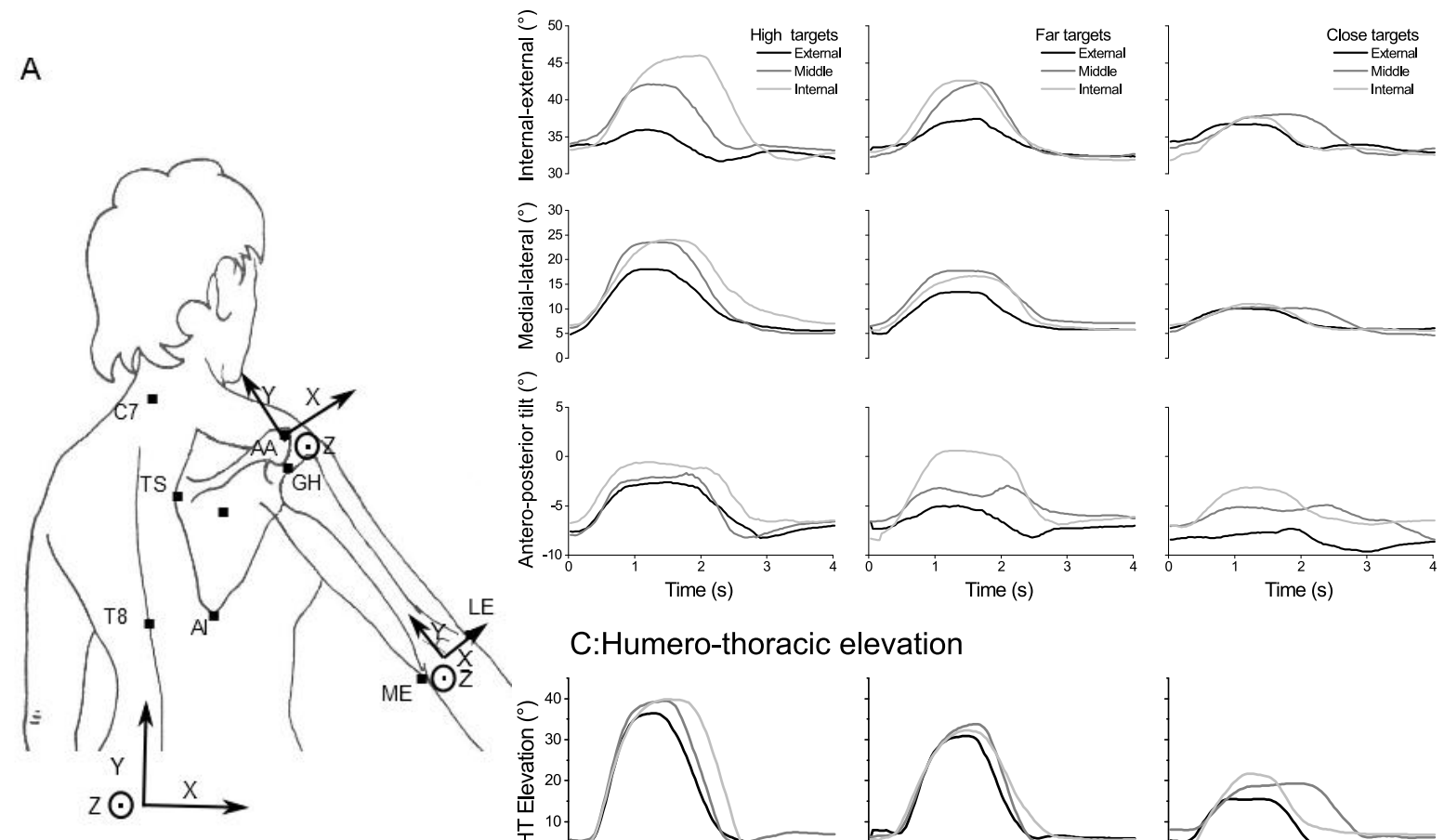

C:Humero-thoracic elevation
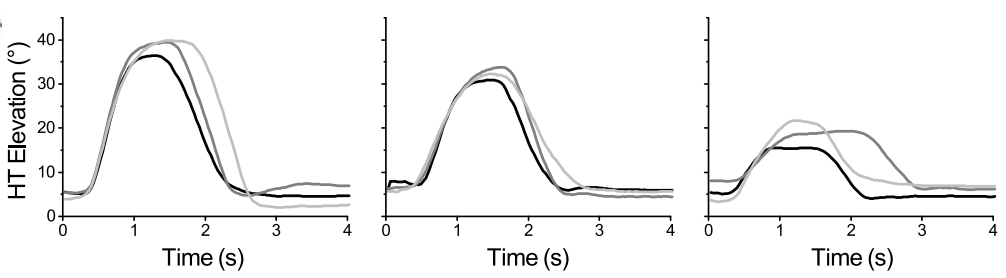
Figure 3: Comparison of initial and final trunk and shoulder postures for each target.

The graph shows the range of motion in the three Euler angles which describe the orientation of the Trunk and Scapulo-thoracic joint (ST) and elevation in the Gleno-humeral (GH) joints. The initial values are indicated by thick lines. For the sake of clarity, only the results for the right side are displayed. The directions (Int: internal, Mid: middle, Ext external) and the distances (High, Far, Close) of the targets are indicated on the abscissa. Each bar represents the mean (and SEM) of the 10 subjects. The trunk is vertical at $90^{\circ}$ (greater values indicating extension), positive values indicate left trunk bending and left axial rotation. Higher positive values indicate ST internal and lateral rotations and posterior tilt, GH elevation.

\section{Trunk}
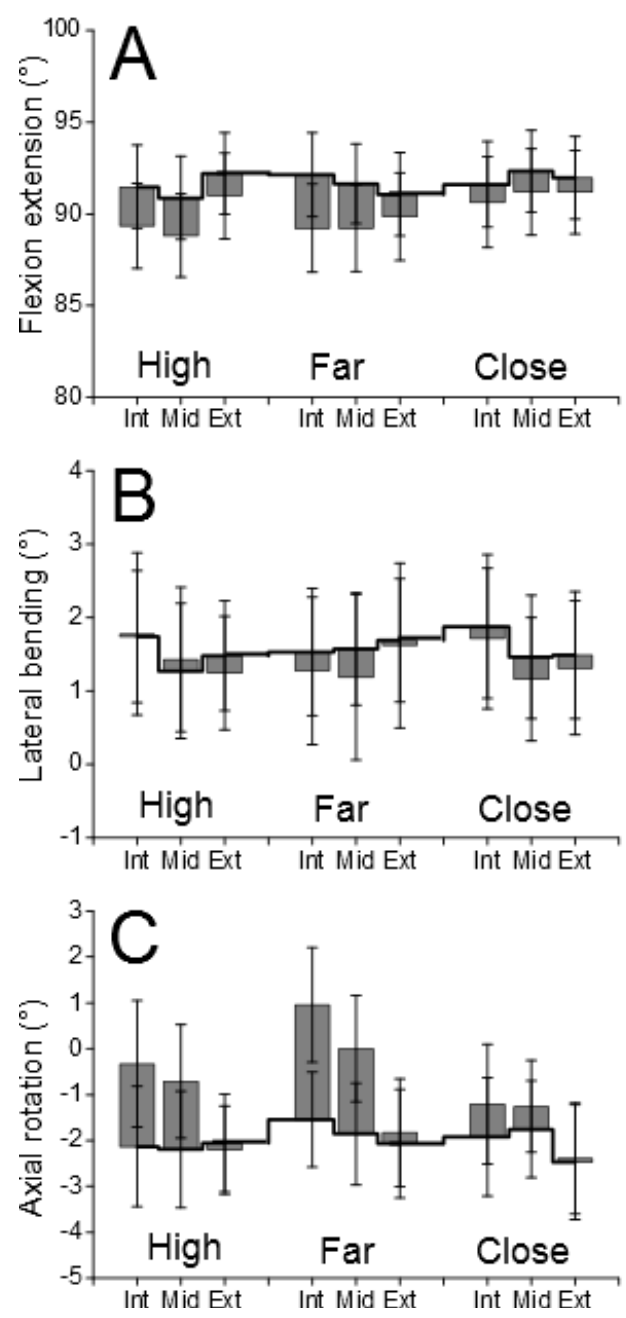

Scapulo-thoracic
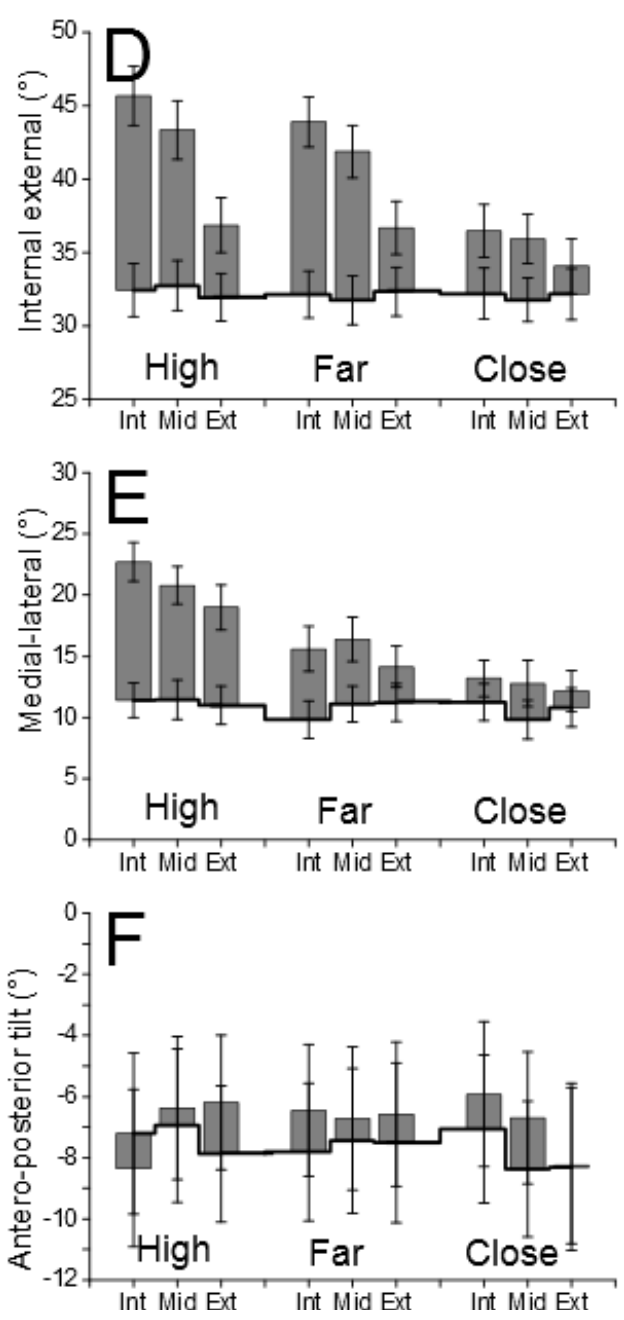

Gleno-humeral

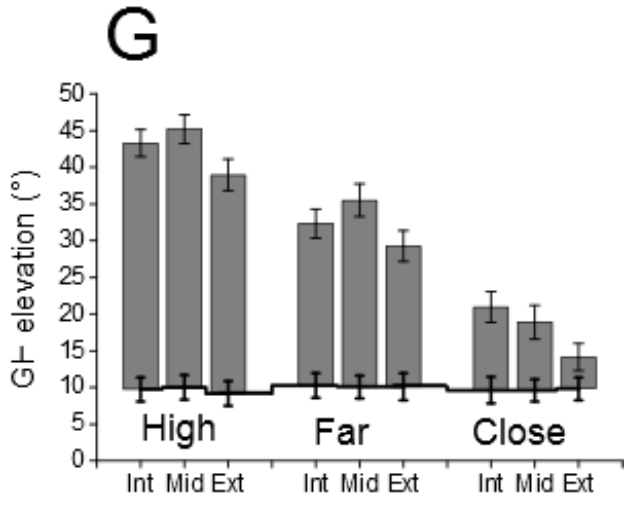


Figure 4: 3D displacement of the center of the scapula.

CS is the geometrical center of the scapula relative to the thorax. The targets are indicated as in Figure 2. Each bar represents the mean (and SEM) of the right side in the 10 subjects.
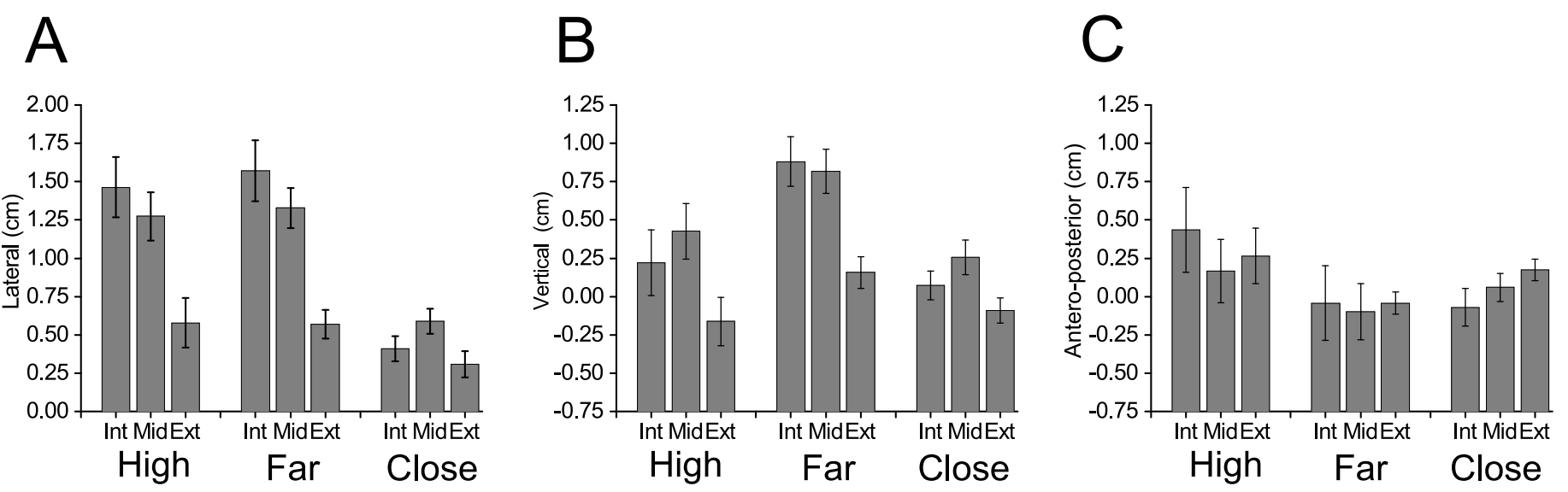
Figure 5: Scapulo-humeral rhythm

Amount of global rotation in GH (triangles) and ST (circles) as a function of global HT rotation (black symbols represent the right side, open symbols the left side). Each symbol represents the data for one target reached by one hand of one subject. The regression lines are indicated for the right (full line) and left sides (stippled line).

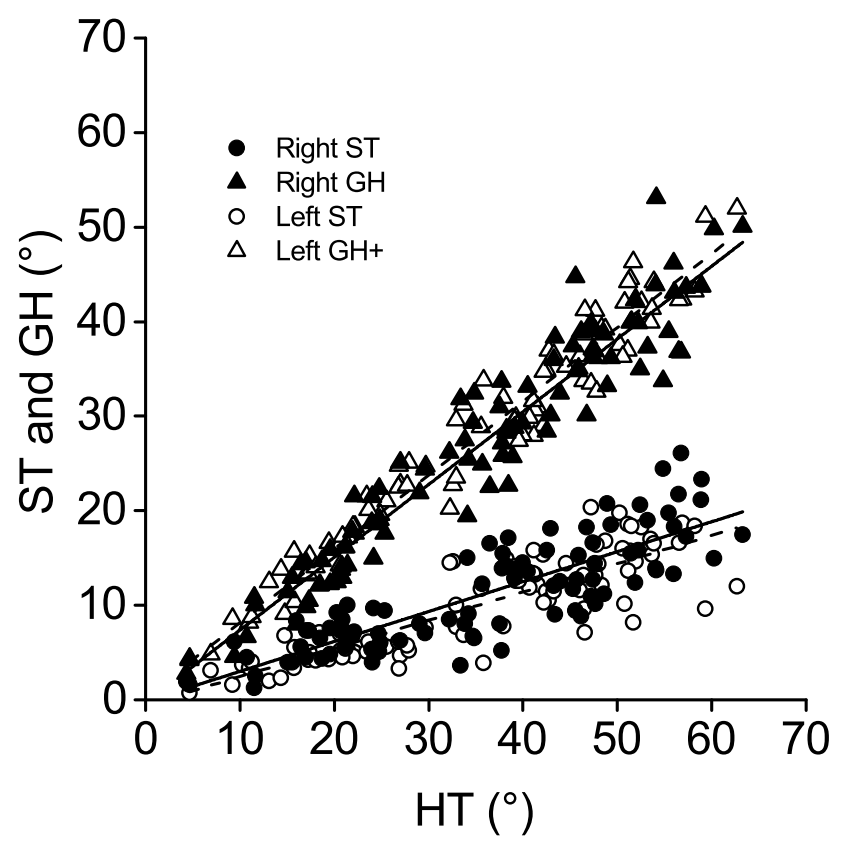


Figure 6: Direct kinematic analysis: projection of the final position of the pointer in space.

A: horizontal projection (the far and high targets appear superimposed); B: frontal projection (the far and close targets appear superimposed). Each point represents the 3D position of the pointer in space, relative to the initial position: black symbols represent the measured position; grey symbols the output of the basic direct model; open symbols the output of the reduced model without scapular rotation. Each point represents the mean (and SEM) of the right side of the 10 subjects.

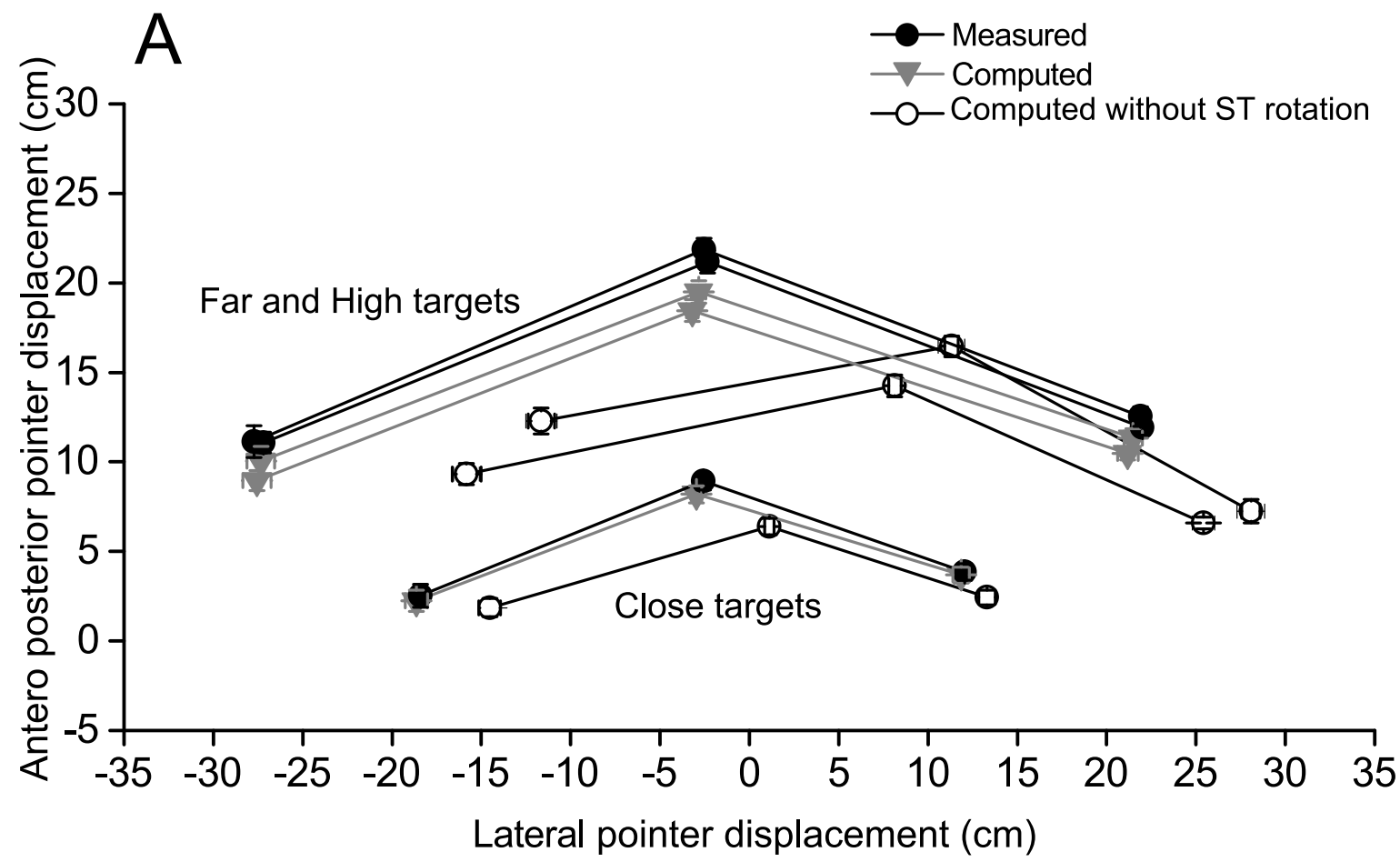

B

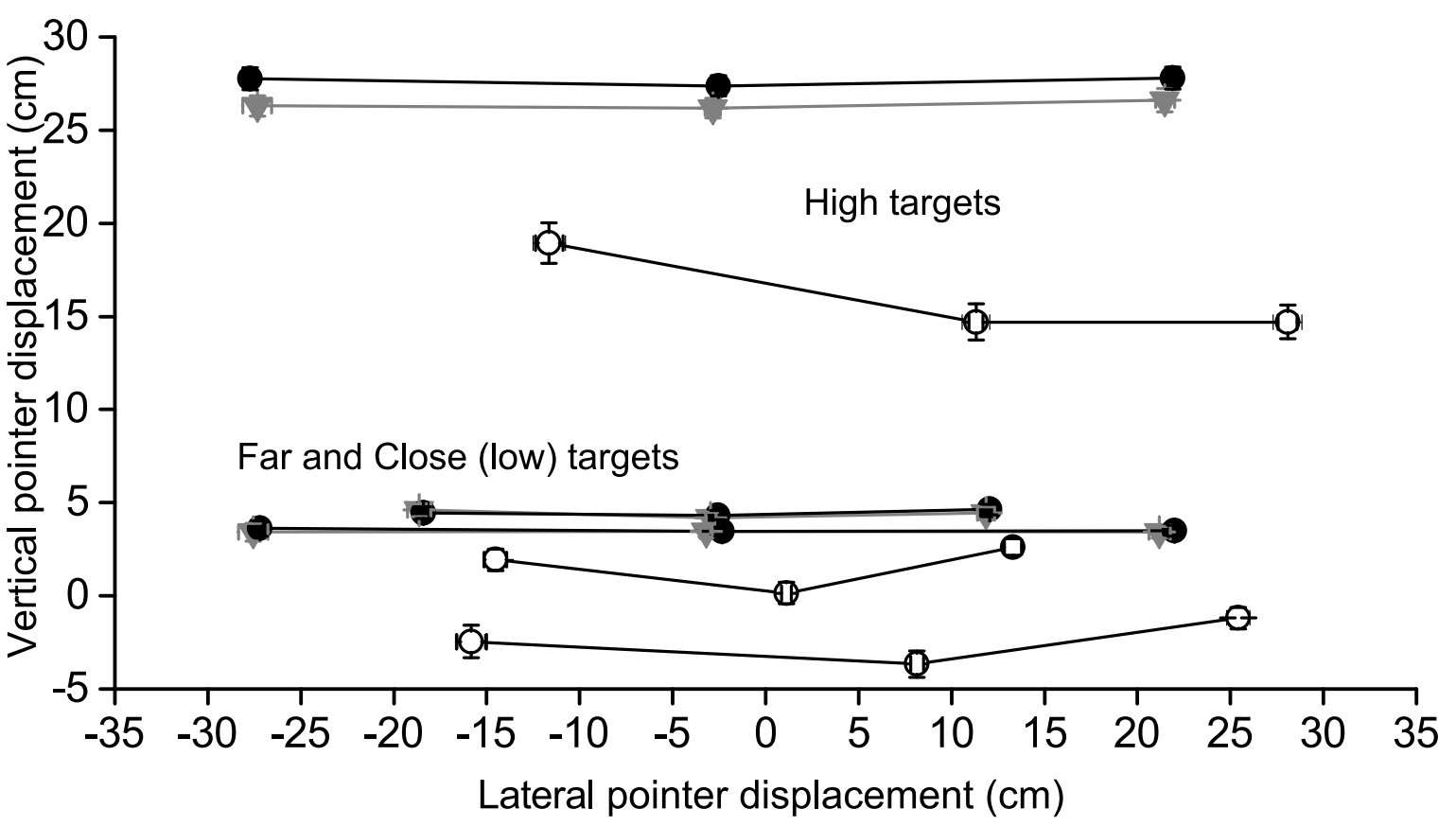


Figure 7: Direct kinematic analysis: global displacement of the pointer.

The black symbols indicate the measured displacement; the grey symbols the output of the basic direct computation and the open symbols the output of the reduced model without scapula rotation. Each symbol represents the mean (and SEM) of the right side in the 10 subjects.

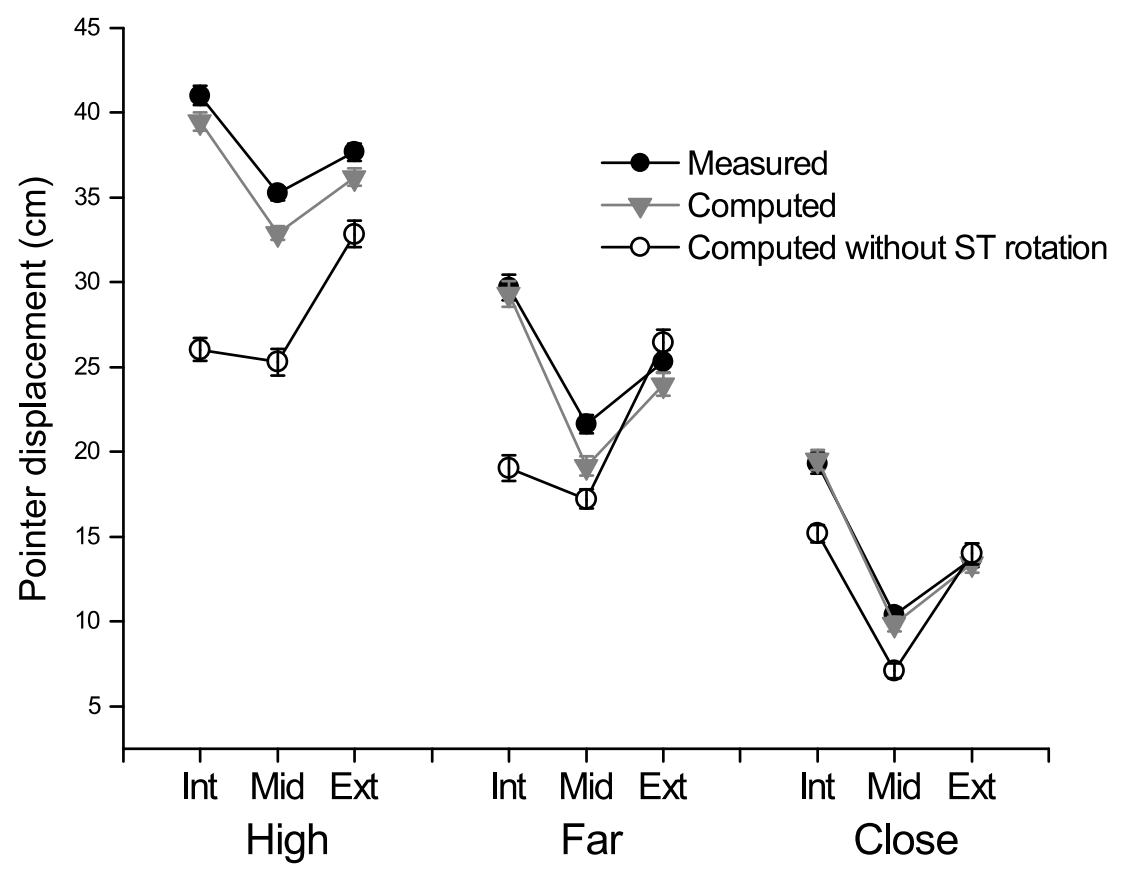

